\title{
Radiation dimming and decreasing water clarity fuel underwater darkening in lakes
}

Yunlin Zhang ${ }^{1,2 *}$, Boqiang Qin ${ }^{1,2 *}$, Kun Shi ${ }^{1,2}$, Yibo Zhang ${ }^{1,2}$, Jianming Deng ${ }^{1,2}$, Martin Wild ${ }^{3}$, Lin

$\mathrm{Li}^{4}$, Yongqiang Zhou ${ }^{1,2}$, Xiaolong Yao ${ }^{1,2}$, Miao Liu ${ }^{1,2}$, Guangwei Zhu ${ }^{1,2}$, Lu Zhang ${ }^{1,2}$, Binhe $\mathrm{Gu}^{5}$, Justin D. Brookes ${ }^{6}$

1 Taihu Laboratory for Lake Ecosystem Research, State Key Laboratory of Lake Science and Environment, Nanjing Institute of Geography and Limnology, Chinese Academy of Sciences, Nanjing 210008, China

2 University of Chinese Academy of Sciences, Beijing 100049, China

3 Institute for Atmospheric and Climate Science, ETH Zurich, Zurich, Switzerland

4 Department of Earth Sciences, Indiana University-Purdue University Indianapolis, 723 W. Michigan St, SL118, Indianapolis 46202, USA

5 Soil and Water Science Department, University of Florida, Gainesville, Florida 32611, USA

6 Water Research Centre, Environment Institute, School of Biological Science, University of Adelaide, 5005 Adelaide, Australia

*Corresponding author: Yunlin Zhang, Email: ylzhang@niglas.ac.cn; Boqiang Qin, Email: qinbq@niglas.ac.cn, Nanjing Institute of Geography and Limnology, Chinese Academy of Sciences, 73 East Beijing Road, Nanjing 210008, P. R. China, Tel: +86-25-86882198, Fax: +86-25-57714759

This is the author's manuscript of the article published in final edited form as:

Zhang, Y., Qin, B., Shi, K., Zhang, Y., Deng, J., Wild, M., Li, L., Zhou, Y., Yao, X., Liu, M., Zhu, G., Zhang, L., Gu, B., \& Brookes, J. D. (2020). Radiation dimming and decreasing water clarity fuel underwater darkening in lakes. Science Bulletin, 65(19), 1675-1684. https://doi.org/10.1016/j.scib.2020.06.016 


\section{Abstract:}

Long-term variability in aerosols and the associated declined incident total radiation, and anthropogenic disturbances and excessive nutrients loadings induced declined water clarity can profoundly affect the underwater light environment in aquatic ecosystems. However, the affecting mechanism and relative contribution of radiation dimming and decreasing water clarity to underwater light environment across nationwide (or worldwide) scale remains largely unknown. Here we present a comprehensive dataset of unprecedented scale in China's lakes to address the combined effects of radiation dimming and decreasing water clarity on underwater darkening. Longterm data indicated that total radiation and sunshine duration decreased by $5.8 \%$ and $7.9 \%$ respectively after 2000 compared to 1961-1970, resulting in net radiation dimming. An in situ Secchi disk depth (SDD) dataset in 170 lakes showed that mean SDD significantly decreased from $1.80 \pm 2.19 \mathrm{~m}$ before 1995 to $1.28 \pm 1.82 \mathrm{~m}$ after 2005. SDD remote sensing estimation for 641 lakes with areas $\geq 10 \mathrm{~km}^{2}$ showed that SDD markedly decreased from $1.26 \pm 0.62 \mathrm{~m}$ during 1985 1990 to $1.14 \pm 0.66 \mathrm{~m}$ during 2005-2010. Radiation dimming and decreasing water clarity jointly caused an approximately $10 \%$ decrease in average available PAR in the euphotic layer. Our results showed a more important role in underwater darkening of decreasing water clarity than radiation dimming. A meta-analysis of long-term SDD observation data from 61 various waters further elucidate a global extensive underwater darkening. Underwater darkening implies declined water quality for potable water supplies, recession in macrophytes and benthic algae, as well as declined benthic primary production, fishery production, and biodiversity.

Key words: radiation dimming, underwater darkening, Secchi disk depth, remote sensing 


\section{Introduction}

Solar radiation reaching the Earth's surface is the predominate energy source to support life, with profound impacts on surface temperature, evaporation, the hydrological cycle, and the structure, function and service of terrestrial and aquatic ecosystems ${ }^{[1-5]}$. In the past six decades, radiation dimming have been observed worldwide, causing a decrease of $4 \%$ to $6 \%$ in surface total radiation, due to air pollution and associated increased aerosol caused by intense human activities ${ }^{[6-9]}$. Since the 1990's, there has been a partial recovery in Europe and North America, known as radiation brightening, due to the increase of atmospheric clear-sky transparency ${ }^{[1,9]}$. However, current surface total radiation worldwide remains markedly lower than that in the 1950 s, despite 20 years of radiation brightening ${ }^{[10,11]}$.

In China from 1960 to 1990, there was a marked dimming in surface total radiation nationwide while some studies in the 1990 s reported a slight recovery in brightening ${ }^{[1,6]}$. However, in the early years of 2000s there was renewed dimming, which was partially attributed to a doubling in consumption of coal in China between 2002 and $2007^{[9,10]}$. A study in 2018 indicated that the transition from dimming to brightening in China may have only occurred after 2005 based on carefully homogenized data ${ }^{[8]}$. In China, the high levels of air pollution have counteracted the effects of the radiation brightening since 1990, contrasting with the results from Europe and North America.

Surface total radiation, or more specifically, its photosynthetic active radiation (PAR, $400-$ $700 \mathrm{~nm}$ ) is the primary driver of primary production. As PAR is proportional to total radiation, the decrease in PAR caused by radiation dimming may decrease carbon uptake of the biosphere and affects the carbon cycle. Furthermore, the gross flux of carbon taken up during photosynthesis is 
positively and linearly correlated with PAR, and a significant decrease in surface total radiation and PAR can have a marked effect on the role of vegetation as a carbon sink ${ }^{[3,12]}$.

Although nutrient limitation is an important paradigm for aquatic plants growth in lakes, the importance of light availability is often underestimated especially for wide distribution nutrientpoor lakes ${ }^{[13,14]}$. In aquatic ecosystems, both phytoplankton and aquatic macrophytes depend on underwater radiation amount for photosynthesis ${ }^{[14-16]}$, and thus both biomass and primary production are sensitive to light availability and underwater darkening ${ }^{[17]}$. Underwater darkening could greatly induce benthic primary production decrease, food resources destruction and predatory environment deterioration for those photosensitive aquatic organisms ${ }^{[14,18,19]}$. However, few studies have assessed the effects of underwater darkening on aquatic ecosystems ${ }^{[17]}$. For aquatic ecosystems, the underwater darkening can be caused by a combination of radiation dimming and decreasing water clarity. In summary, water clarity is jointly determined by pure and three optically active substances including phytoplankton, non-phytoplankton particle matter, and dissolved organic matter. Therefore, any processes resulting in the changes in concentration and composition of three optically active substances will affect water clarity including eutrophication, pollution, browning, land use change and increased soil erosion in the catchment caused by vegetation destruction.

Determining water clarity, Secchi disk depth (SDD), is a quick and useful way to evaluate the underwater light environment and the trophic state of aquatic ecosystems ${ }^{[20-22]}$. Traditional in situ SDD measurement using Secchi disk has been carried out for more than 150 years ${ }^{[20]}$. In the past decades, remote sensing is considered as an important supplement or substitute to obtain an overview of the temporal-spatial patterns of SDD due to its unparalleled advantages of collecting measurements from historical and large-scale perspectives ${ }^{[23]}$. Many arduous efforts have been 
made to develop a series of empirical, semi-empirical, and semi-analytical algorithms to estimate SDD and explore the long-term change over different inland waters using Landsat, MERIS, MODIS, etc ${ }^{[22,24-27]}$. Decrease in water clarity has been linked to the reduced water quality, the loss of macrophytes and benthic algae, a decrease in primary production, decreases in habitat and fishery production, biodiversity loss, and a decrease in recreational value ${ }^{[14,19,28,29]}$. Some previous efforts have attempted to explore long-term trends in SDD and elucidate the potential effects for many

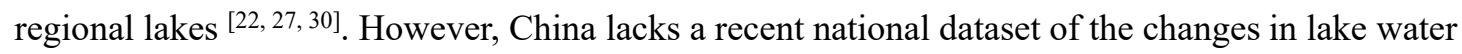
clarity, which prevents a comprehensive and systematic assessment of national trends, and limits our understanding of changes in carbon source or sink dynamics and other ecosystem changes. More importantly, no published study around the world has examined the combined contributions of radiation dimming and decreases in water clarity on underwater darkening.

We propose a new concept that radiation dimming and decreasing water clarity jointly result in accelerating underwater darkening and decreasing water clarity plays a more important role than that of radiation dimming. We pursue three specific objectives to: 1) quantify whether there has been a decrease in incident total radiation and sunshine duration throughout China; 2) quantify whether there has been a nation-wide decrease in lake water clarity; and 3) elucidate the combined or interactive effects of radiation dimming and decreasing water clarity on the underwater light environment in lakes, and discuss the implications for lake production and the carbon dynamics. Our results provide a new perspective on underwater darkening and future carbon dynamics study in lakes. Considering the complex and different affecting processes of SDD for specific lake, our study has not attempted to elucidate the specific affecting factors of SDD.

\section{Materials and methods}




\section{Surface total radiation and sunshine duration}

Surface total radiation data was examined from a 53-year record from 1961 to 2013, at 116 radiation observation station in China, which was the new and complete total radiation data that we could collect. Data came from archives of the National Meteorological Information Center of the China Meteorological Administration (NMIC/CMA). Detailed information on station names, codes, altitude, starting and ending years of the observation period, and linear fitting of yearly total radiation versus year, is provided in Table S1 (Fig. S1). The data availability was: complete data for all 53 years for 57 of the 116 stations; data for at least 26 years (half the study period) for 24 stations; and for the remaining 35 stations, data were available for 20 to 24 years. These data have been widely used to trace the long-term trends of total radiation in China ${ }^{[6-8]}$. Considering that sunshine duration is also important parameter characterizing radiation dimming or brightening, we also obtained sunshine duration data from 839 meteorological stations in China, including the 116 radiation observation stations (Fig. S1). Sunshine duration data of 839 stations is continuing and complete for the period from 1961 to 2013.

\section{In situ SDD measurement: nation-wide, and for four typical lakes}

To provide a unique insight into the long-term changes in the underwater light environment in China's lakes, we therefore compiled three datasets from publicly available data: in situ SDD measurements from national lakes investigations and literature; in situ SDD measurements from long-term studies of four lakes over the past few decades, and remotely estimated SDD during the two periods of 1985 to 1990 and 2005 to 2010 .

Temporal changes in SDD were determined by comparing the values for 170 lakes in China before 1995 with those after 2005 (Table S2). These time periods were determined by the availability 
of data from the first and second nationwide lake investigations, which were undertaken from the 1960s to 1980 s, and 2005 to 2010 , respectively. The 170 lakes in this dataset ranged from $<1 \mathrm{~km}^{2}$ to $>4000 \mathrm{~km}^{2}$ in water area and from $<1 \mathrm{~m}$ to $>150 \mathrm{~m}$ in mean depth (Table S2), covered different trophic states, and represented five previously-defined geographic lake zones in China ${ }^{[31-33]}$.

The regional survey data were supplemented with more intensive SDD monitoring data over 30 to 37 years with an interval of monthly measurement from four lakes with different trophic states and SDD ranges: Lake Fuxianhu (1980-2016) - oligotrophic, Lake Qiandaohu (1988-2016) oligotrophic- mesotrophic, Lake Erhai (1985-2016) - mesotrophic, and Lake Gehu (1992-2016) eutrophic ${ }^{[33-35]}$.

\section{Remote sensing estimation of SDD before 1995 and after 2005}

The uneven geographical distribution of in situ SDD data from historical investigations and the published literatures prompted us to seek data from remote sensing, from which we could estimate SDD for China's lakes. We used remote sensing data from Landsat images with $30 \mathrm{~m}$ spatial resolution, for two periods, 1985 to 1990 and 2005 to 2010, representative of conditions before 1995 and after 2005, respectively and consistent with the time periods for the comparison of the in situ SDD data. Considering the $30 \mathrm{~m}$ spatial resolution and complex lake shoreline of some lakes, we focused on 641 lakes with water areas $\geq 10 \mathrm{~km}^{2}$ to reduce the uncertainty in estimates.

A total of 26321 high-quality Landsat 5 TM and 7 ETM+ scenes image of China's lakes were downloaded from the United States Geological Survey (USGS) (http://glovis.usgs.gov/) in summer and spring (July 1 to September 30) during two periods of 1985 to 1990 and 2005 to 2010. We selected these seasons because there is no ice cover for all China's lakes and the sky is clear in most conditions. On average, more than 2000 scenes image in every year are used, which normally meet 
the need of SDD estimation for nationwide lakes. More importantly, we only compare the difference of two periods of 1985 to 1990 and 2005 to 2010 to reduce the errors and uncertainties of data as far as possible. Of course, there are some uncertainties for remote sensing data because our dataset only includes four months in summer and spring seasons. The Landsat 5 TM and 7 ETM+ images were level-1 processed, meaning that they received uniform radiation and geometry correction. The images were then processed in two steps: 1) radiometric calibration and 2) atmospheric correction. The radiometric calibration converted the raw digital number into physically meaningful radiance or reflectance of Landsat $5 \mathrm{TM}$ and 7 ETM+ images; the atmospheric correction eliminated the influence of atmospheric absorption and scattering.

To retrieve an accurate remote sensing reflectance used to estimate SDD, based on the visible bands of the Landsat $5 \mathrm{TM}$ and $7 \mathrm{ETM}+$, we used an alternative correction scheme (second simulation of satellite signal in the solar spectrum: 6S model) with the aid of Terra/MODIS aerosol information. The SDD is strongly correlated with the responses in the blue and red bands of Landsat TM/ETM+ data ${ }^{[36,37]}$. To calibrate and validate our SDD estimation model, we used two complete independent datasets. We obtained the in situ SDD from 225 China's lakes covering from shallow to deep, from small to large, and from oligotrophic to eutrophic in different months and seasons, and used 887 samples to calibrate and 246 samples to validate our SDD remote sensing estimation model ${ }^{[38]}$. For the calibration dataset, SDD ranged from 0.01 to $14.00 \mathrm{~m}$ with a mean value of 1.57 $\pm 1.95 \mathrm{~m}$. For the validation dataset, SDD ranged from 0.05 to $6.70 \mathrm{~m}$ with a mean value $1.51 \pm$ $1.74 \mathrm{~m}$ falling in the SDD range of the calibration dataset.

For the large calibration dataset (887 samples), there was a highly significant power function correlation $\left(r^{2}=0.73, p<0.001\right)$ between the remote sensing reflectance of red Band $3(630-690 \mathrm{~nm})$ 
derived from Landsat 5 TM, 7 ETM+ and SDD. The independent validation dataset showed that the measured and estimated SDD were distributed along the 1:1 line with the mean relative error and normalized root mean square error of $34 \%$ and $55 \%$, respectively, indicating that the power function model based on the red band of Landsat reflectance could be well used to estimate SDD of China's lakes covering SDD from less than $0.1 \mathrm{~m}$ to more than $10 \mathrm{~m}$. Detailed information about the model calibration, validation, and assessment is found in our previous study ${ }^{[38]}$. Overall, the SDD estimation model precision in our study was accepted compared to previous similar studies ${ }^{[24-27]}$.

\section{Literature data on marked decrease in long-term SDD}

Meta-analysis from the literature is a good way to summarize the available evidences to provide a more robust result than a single study. In detail, we extracted, from the published literatures, long-term SDD data for various waters including oceanic, coastal and inland waters around the world, and compiled a dataset of changes in SDD. Specifically, we searched the Science Citation Index (SCI) Expanded database (1900-2019), and the China Academic Journals Full-text Database (1960-2019), using the topic words (“Secchi” or "water transparency" or "water clarity*”) and ("long term" or "long-term").

\section{Measurement and calculation of underwater PAR}

The underwater PAR profile and SDD were synchronously measured in diverse waters, comprising 25 lakes from very clear (Lake Fuxianhu) with SDD $>6.0 \mathrm{~m}$ to highly turbid waters (Lake Taihu) with SDD $<0.2 \mathrm{~m}$. Down-welling PAR was measured on the sunny side of the boat, with the sensor extended $0.5 \mathrm{~m}$ from the boat to reduce the influence of reflectance from the vessel on the underwater PAR. Measurement of underwater PAR was generally carried out between 8:30 and 17:00 on cloudless days. PAR measurements were made at 6-30 layers according to water depth 
of the different lakes.

The underwater PAR was measured using a Li-Cor 192SA underwater quantum sensor connected to a Li-Cor 1400 data logger. The Li-Cor 192SA was installed in a lowering frame which provided stability for proper orientation of the sensor, and minimized shading effects. Using the instantaneous mode of the LI-1400 data logger, three values were recorded at 1-minute intervals for each depth. Their mean value was considered as the PAR intensity for that depth, to minimize the effect of wind-generated waves on measurement of underwater PAR.

The diffuse attenuation coefficients for the downward irradiance, $K_{\mathrm{d}}(\mathrm{PAR})$, were determined as the slope of the linear fitting of the log-transformed profile underwater irradiance $v s$ depth ${ }^{[39]}$. We accepted only $K_{\mathrm{d}}(\mathrm{PAR})$ values from regressions with the determination coefficient $\left(r^{2}\right)$ more than 0.98 . The number of depths used in these regressions was 6-30, depending on the penetration depth and water depth.

To correlate SDD with $K_{\mathrm{d}}(\mathrm{PAR})$, and calculate euphotic depth (the depth at which PAR is $1 \%$ of its value at the water surface), a dataset of 1219 SDD from $<0.1 \mathrm{~m}$ to $>8.0 \mathrm{~m}$ was used encompassing most of the range of lake water clarity observations used worldwide ${ }^{[22,30]}$.

\section{'Hu Huanyong' Line}

The 'Hu Huanyong' Line was proposed by the famous population geographer Hu Huanyong in 1935. The line ran from the city of Aihui (Heihe) in the northeast to Tengchong county in the southwest, which is basically coincided with the $400 \mathrm{~mm}$ precipitation isoline. The statistical data in 2010 showed that the southeast region of the 'Hu Huanyong' Line (except for Hong Kong, Macao, and Taiwan province) covered $36.0 \%$ of the total area of mainland but gathered $94.0 \%$ of the population and contributed to $95.7 \%$ of the national gross domestic product in China. Therefore, 
this line can be regarded as an important geographical, economic, social, and human activity intensity division line in China ${ }^{[40]}$.

\section{Data statistical analyses}

All statistical analysis was performed using Statistical Package for the Social Sciences software (SPSS 20, Chicago, IL). Significance level $p \leq 0.05$ was considered statistically significant. For simplicity and easy comparison, long-term trend variations of total radiation, sunshine duration, and SDD were performed based on linear regression analysis. The non-parametric Mann-Whitney (MW) statistic test is more suitable for non-normally distributed data so it may be not sensitive to the distribution type of sample data. Therefore, we use MW statistic test to assess the significance of a shift in mean values.

\section{Results}

\section{Radiation dimming in China}

There were marked trends in long-term yearly mean total radiation at the 116 individual stations in China during 1961-2013 (Fig. S2). Total radiation decreased at 91 stations (78.4\% of stations), with a statistically significant decrease recorded for 50 stations (43.1\%). In contrast, there was an increase in total radiation at 25 stations (21.6\%), and with a statistically significantly increase at only 4 stations (3.4\%). For 14 of 25 stations with increasing trends, total radiation observations were only available for the period from the 1980 s to 2013 , thus the reported increases are from the second half of the 53 year time span (Table S1). Among the 57 stations with continuous data for the 53 years from 1961 to 2013 , the yearly mean total radiation significantly decreased $\left(r^{2}=0.27, p \leq\right.$ 0.01). Furthermore, among these 57 stations, the yearly mean total radiation in 2001 to 2013 was on average $5.8 \%$ lower than that in 1961 to 1970 . 
There was also a significant decrease in yearly mean sunshine duration at 505 of 839 stations in China (60.2\% of the total) (Fig. 1), with a mean decrease rate of $4.59 \mathrm{~h} / \mathrm{yr}$ from 1961 to 2013 when all the data of 839 stations was pooled $\left(r^{2}=0.68, p<0.001\right)$ (Fig. S3). The sunshine duration decreased by $7.9 \%$ when comparing $2001-2013$ with $1961-1970$, which was greater than $5.8 \%$ for the total radiation. Overall, significant decreasing trend of sunshine duration was observed in the southeastern region but nonsignificant decreasing even slight increasing trend was found in the northwestern region. The mean decreasing slope was $6.21 \pm 3.75 \mathrm{~h} / \mathrm{yr}$ and $3.03 \pm 3.98 \mathrm{~h} / \mathrm{yr}$ in the southeastern and northwestern regions along the 'Hu Huanyong' Line (Fig. 1).

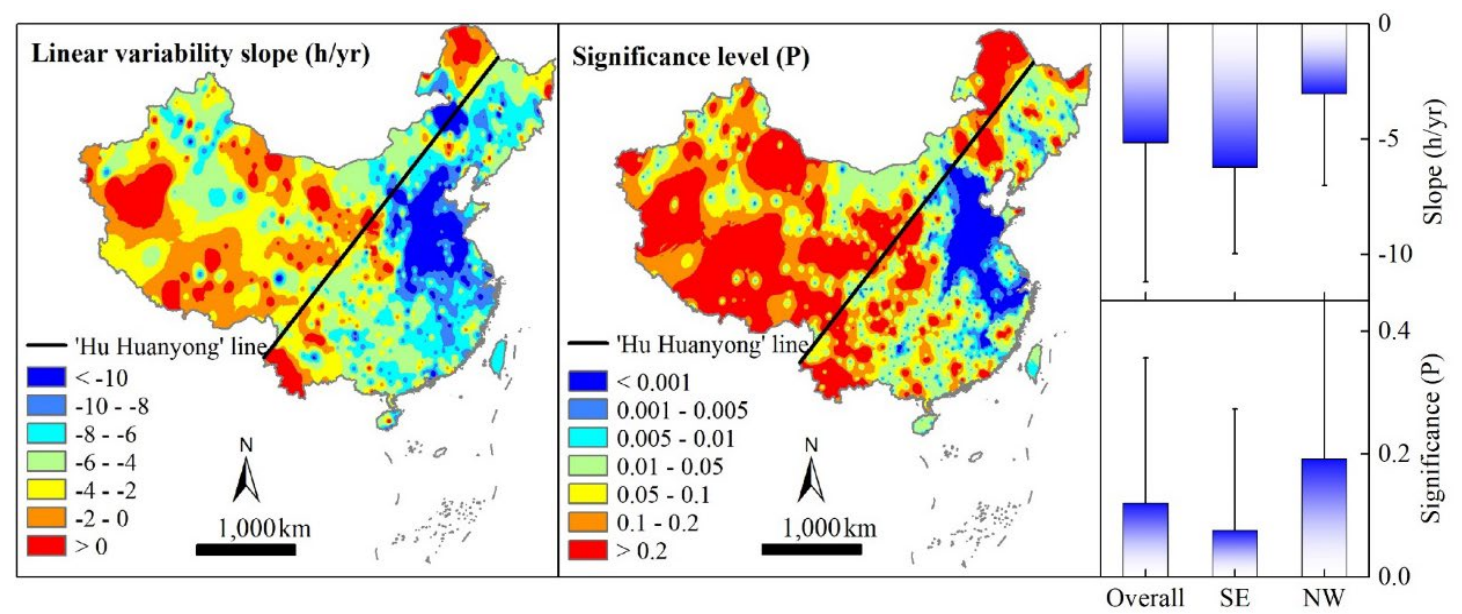

Fig. 1. Spatial patterns and comparison of linear variability slope and significance level of yearly mean sunshine duration vs year at 839 observation stations in China 1961 - 2013. Linear fitting slope (left), significance level (middle), and comparison of slope and significance level in the whole nationwide, southeastern (SE) and northwestern (NW) of the 'Hu Huanyong' Line (right).

\section{Decreasing SDD in China's lakes}

The dataset from two national lake investigations and the literatures cover a large variability of SDD from 0.12 to $13.3 \mathrm{~m}$ from 1960s to 1995 partially demonstrating different trophic gradients from oligotrophic to hyper-eutrophic. A comparison of all 170 lakes revealed a SDD decrease in 
130 lakes (76.5\%), an increase in 40 lakes (23.5\%) during 2005 to 2016 when compared with the 1960s to 1995 . The number of lakes with a SDD decrease was more than three times that of lakes with a SDD increase. Among all 170 lakes with in situ SDD data (uncertainty $\leq 0.05 \mathrm{~m}$ ), the average SDD significantly decreased by $28.9 \%$ from $1.80 \pm 2.19 \mathrm{~m}$ from 1960 s to 1995 to only $1.28 \pm 1.82$ m during 2005-2016 ( $p<0.05$, MW test) (Fig. 2).
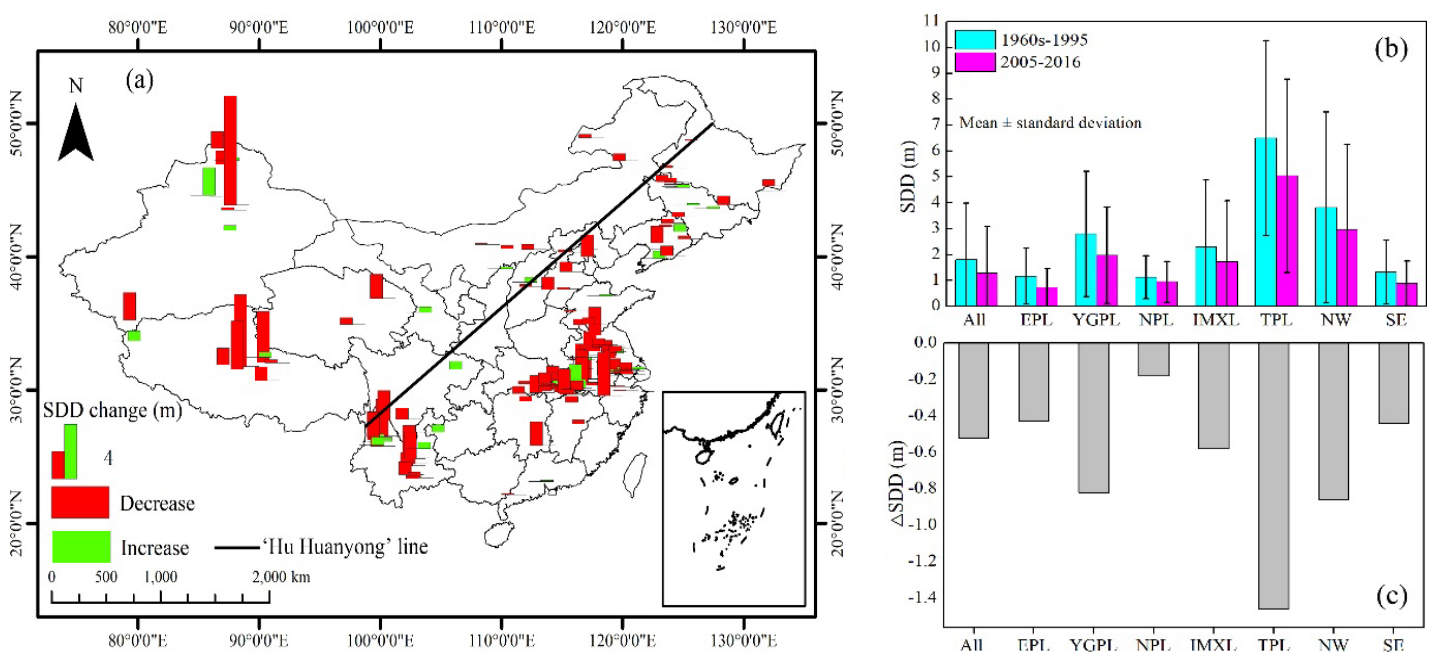

Fig. 2 Spatial distribution of SDD differences during 2005-2016 compared to 1960s-1995 (a),

SDD comparison before 1995 compared to after 2005 according to the five geographic lake zones and the 'Hu Huanyong' Line (b, c) based on the in situ dataset of 170 lakes in China; All: all lakes; EPL: Eastern Plain Lake zone; YGPL; Yunnan-Guizhou Plateau Lake zone; NPL:

Northeast Plain Lake zone; IMXL: Inner Mongolia-Xinjiang Lake zone; TPL: Tibetan Plateau Lake zone; NW and SE represents results for lakes in the northwestern and southeastern regions of the 'Hu Huanyong' Line.

Spatially, SDD decreased more in lakes located in the Eastern Plain Lake (EPL) zone than those in other zones (Fig. 2). The mean SDD decreased by $33.3 \%$ and $22.5 \%$ in the southeastern and northwestern regions of the 'Hu Huanyong' Line. For the 130 lakes with a SDD decrease, there was a significant decrease of $41.3 \%$ from $1.89 \pm 2.12 \mathrm{~m}$ during $1960 \mathrm{~s}-1995$ to $1.11 \pm 1.46 \mathrm{~m}$ during 
2005-2016 ( $p<0.001$, MW test). In contrast, for the 40 lakes with a SDD increase, the nonsignificant increase was from $1.52 \pm 2.40 \mathrm{~m}$ during $1960 \mathrm{~s}-1995$ to $1.84 \pm 2.63 \mathrm{~m}$ during $2005-2016$ $(p>0.05$, MW test).

We compared the spatial distribution of remote sensing-based SDD of lakes in the five geographic lake zones during the two time periods across China with water area $\geq 10 \mathrm{~km}^{2}$ (Fig. 3). There were marked decreases in SDD nationally (from 1.26 to $1.14 \mathrm{~m}$ by $10.1 \%$ ), and significant decreases in SDD in two of the five lake zones including EPL (from 0.72 to $0.46 \mathrm{~m}$ by $57.8 \%$ ), NPL (from 0.55 to $0.36 \mathrm{~m}$ by $52.8 \%)(p<0.01$, MW test), respectively, when comparing the 2005 to 2010 with the 1985 to 1990 data (Fig. 3g, 3m, 3n). In contrast, the remote sensing estimation showed a slight or marked increase in SDD for lakes in YGPL (from 1.15 to $1.17 \mathrm{~m}$ by $1.8 \%$ ), IMXL (from 1.02 to $1.10 \mathrm{~m}$ by $7.1 \%$ ), and TPL zones (from 1.64 to $2.02 \mathrm{~m}$ by $19.0 \%$ ) (Fig. $3 \mathrm{~g}, 3 \mathrm{~m}, 3 \mathrm{n}$ ). This was overall consistent with results from that of the in-situ investigations and literature data, which showed a $22.5 \%$ decrease in SDD for 11 lakes in the TPL zone. In addition, significant decreasing trend of SDD was observed in the southeastern region while an increasing trend was found in the northwestern region along the 'Hu Huanyong' Line (Fig. 3g, 3m, 3n), which was consistent to the long term trend of total radiation and sunshine duration (Fig. 1). 

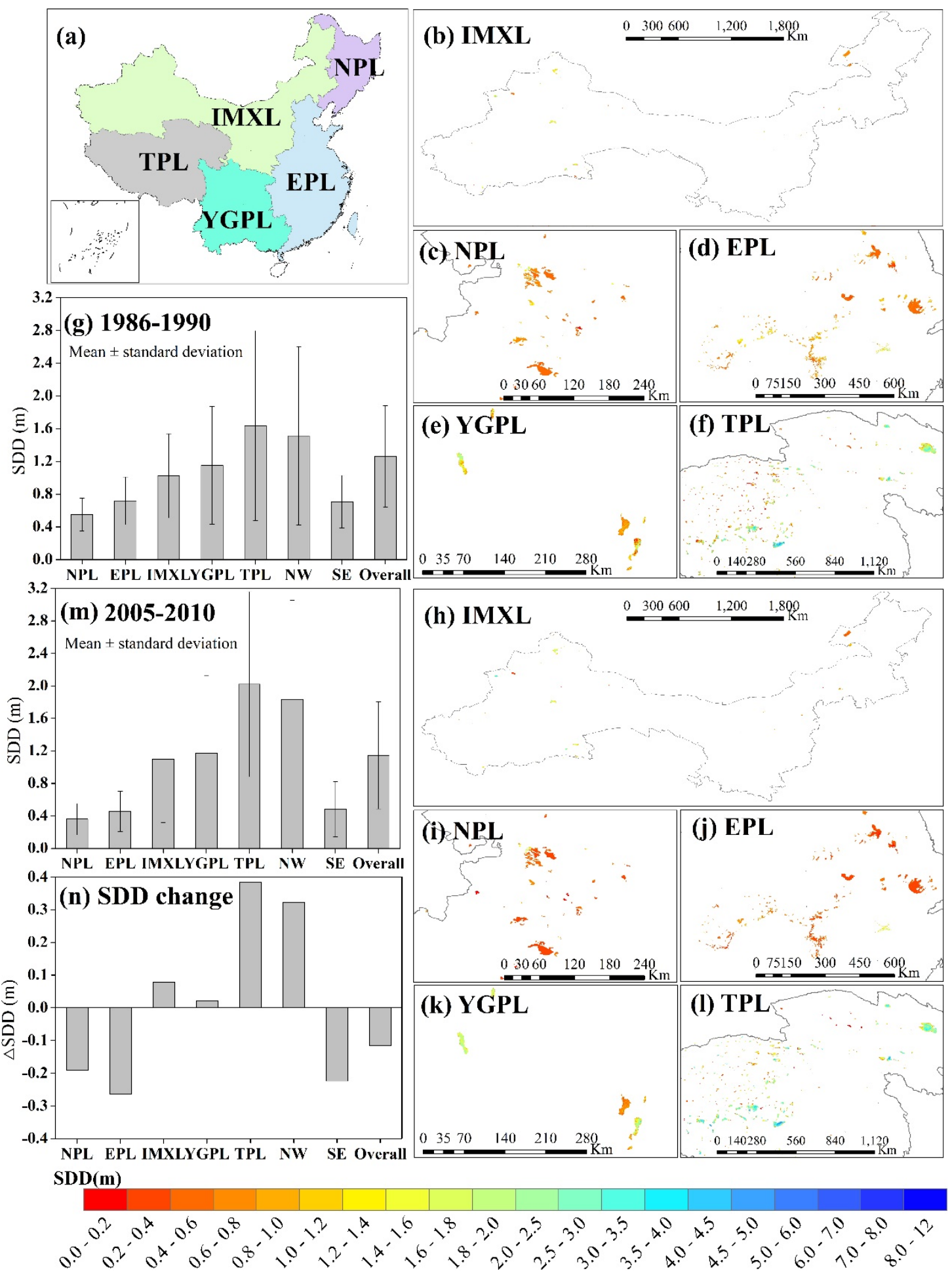

Fig. 3 Distribution of the five geographic lake zones (a), spatial distribution of SDD remote

sensing estimation for five geographic lake zones from 1985 to 1990 (b-f) and from 2005 to 2010

(h-1), mean SDD comparison for five geographic lake zones, southeastern and northwestern

regions along 'Hu Huanyong' line between from 1985 to 1990 and from 2005 to 2010 (g, m, n) for 
641 lakes with water area larger than $10 \mathrm{~km}^{2}$ in China

The long-term, site-specific, SDD monitoring in four different trophic state lakes showed that significant decreases also occurred in the underwater light availability from 1980 to 2016 . Over this period of time, a significant decrease in SDD was recorded in all of the lakes $(p \leq 0.001)$ (Fig. S4). The mean decreasing rate of SDD in each of these four lakes was: Lake Fuxianhu $0.60 \mathrm{~m} /$ decade (1980 to 2016), Lake Qiandaohu 1.09 m/decade (1988 to 2016), Lake Erhai $0.72 \mathrm{~m} /$ decade (1989 to 2016), and Lake Gehu $0.28 \mathrm{~m} /$ decade (1985 to 2016). Based on a linear fitting, decreases of $29.1 \%, 42.2 \%, 57.3 \%$, and $83.2 \%$ occurred in Lake Fuxianhu, Lake Qiandaohu, Lake Erihai, and Lake Gehu, respectively. It was noteworthy that a sharp decrease of SDD was observed around 2004 in Lake Erhai due to eutrophication and the marked increase of phytoplankton biomass.

\section{Correlation between SDD and diffuse attenuation coefficient}

A highly significant correlation was found between SDD and $K_{\mathrm{d}}(\mathrm{PAR})\left(r^{2}=0.935, n=1419\right)$ (Fig. 4a), based on the large dataset covering SDD from $<0.08 \mathrm{~m}$ to $>8.0 \mathrm{~m}$. This result provides strong quantitative support for calculating $K_{\mathrm{d}}(\mathrm{PAR})$ from SDD measurements. Using a power function correlation (Fig. 4a), we calculated that the mean $K_{\mathrm{d}}(\mathrm{PAR})$ values were: (i) 0.81 and 1.13 $\mathrm{m}^{-1}$ before 1995 and after 2005, respectively for in situ observations (national investigations and literature dataset); and (ii) 1.14 and $1.26 \mathrm{~m}^{-1}$ before 1995 and after 2005, respectively for Landsat 5 TM images remote sensing estimation dataset. Overall, $K_{\mathrm{d}}(\mathrm{PAR})$ values calculated from in situ observations were slightly lower than those calculated from Landsat 5 TM images.

\section{Underwater darkening due to radiation dimming and decreasing SDD}

Using the $K_{\mathrm{d}}(\mathrm{PAR})$ values, we calculated the underwater PAR distribution and the relative contributions of radiation dimming and decreasing SDD in euphotic zone of lakes (Fig. 4b). Based 
on in situ field measurements and literature data, the mean euphotic depth was $5.69 \mathrm{~m}$ before 1995 and $4.08 \mathrm{~m}$ after 2005 representing a $28.3 \%$ decrease. The increase of $K_{\mathrm{d}}(\mathrm{PAR})$, from 0.81 before 1995 to $1.13 \mathrm{~m}^{-1}$ after 2005 , resulted in a $7.49 \%$ decrease of average surface PAR in a fixed euphotic layer ( $1 \%$ penetration of light in the water column of 0 to $4.10 \mathrm{~m}$ corresponding to $K_{\mathrm{d}}(\mathrm{PAR})$ value of $1.13 \mathrm{~m}^{-1}$ ), and a $9.60 \%$ loss of average PAR in the layer with $10 \%$ penetration of light in the water column of 0 to $2.05 \mathrm{~m}$. If we consider a $5.8 \%$ decrease of surface total radiation of 2001 to 2013 compared to that of 1961 to 1970 due to radiation dimming, and assume that PAR is proportional to total radiation, we can determine a $8.77 \%$ loss of average surface PAR in the euphotic layer and a $11.85 \%$ loss of average PAR in the layer with $10 \%$ light penetration (Fig. $4 \mathrm{~b}$ ). In comparison, the relative contributions of SDD decreasing and radiation dimming to the decrease of average surface PAR are $85.4 \%$ and $14.6 \%$ in a fixed euphotic layer $(0-4.10 \mathrm{~m}), 81.0 \%$ and $19.0 \%$ in the layer with $10 \%$ light penetration $(0-2.05 \mathrm{~m})$. Therefore, decreasing SDD plays a more important role in underwater darkening than does radiation dimming in China's lakes.
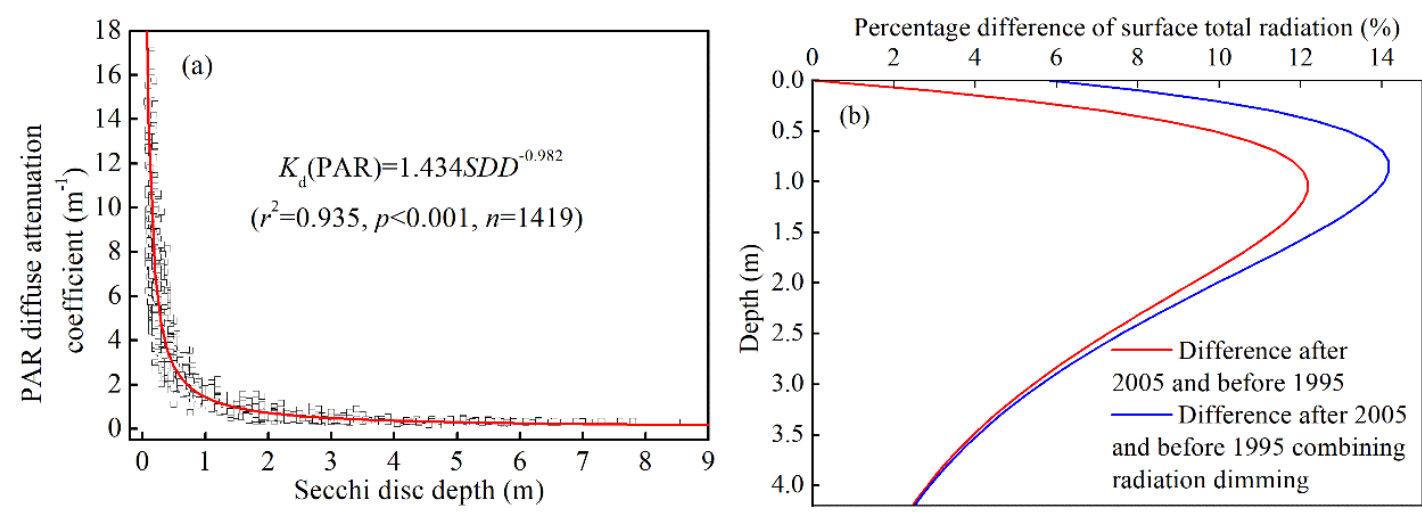

Fig. 4. Correlation between Secchi disk depth and PAR diffuse attenuation coefficient when both were synchronously measured (a) and depth profile of loss of surface total radiation a fixed euphotic layer when comparing data before 1995 and after 2005 from in situ measurements for national investigations and literature dataset (b). 


\section{Discussion}

\section{Radiation dimming}

Our results show these indications: (i) in China, yearly mean total radiation was 5.8\% lower after 2000 compared to 1961-1970 although a slight brightening was observed in a minority of stations (Fig. S2 and Table S1); and (ii) in China, sunshine duration decreased through 2013 (Fig. S3). Severe aerosol and air pollution over China potentially reduce both incident total radiation and sunshine duration ${ }^{[9,41]}$. With the implementation of the "Atmospheric Pollution Prevention and Control Action Plan", atmospheric transparency will be improved to mitigate radiation dimming. However, there are still uncertainties if the action can induce the transition from radiation dimming to radiation brightening over China, because of the influence of increased air pollution and associated dimming which may occur in neighboring, rapidly-developing countries ${ }^{[42,43]}$.

\section{Decrease in SDD}

SDD has been widely used to assess underwater light availability and water quality, and estimate phytoplankton biomass and $\mathrm{CO}_{2}$ fluxes. For example, phytoplankton biomass, commonly expressed using chlorophyll a (Chla) concentration can be derived from SDD measurements, which is closely comparable to those estimated from direct in situ optical measurements or satellite remote sensing ${ }^{[28,44]}$.

We have now reported $28.9 \%$ and $10.1 \%$ decrease in SDD after 2005 compared with that before 1990 for national in situ investigation and remote sensing estimation datasets (Fig. 2, Fig. 3), respectively. Significant SDD decrease was found in the southeastern region along the $\mathrm{Hu}$ Huanyong' Line for both in situ investigation and remote sensing estimation datasets, which reflected SDD decrease was tightly linked to population agglomeration, rapid economic and social 
development, and strong human activities in the southeastern region ${ }^{[40]}$. However, in the past 20 years, extensive lake expansion observed on the Tibetan Plateau due to the warmer and wetter climate may cause some uncertainties to elucidate the long-term trend of SDD in TPL as our remote sensing dataset showed ${ }^{[45]}$, which requires more detailed studies in the future.

Furthermore, this decrease in SDD was accompanied by a 5.8\% decrease in surface total radiation due to radiation dimming, which has led to a decrease of $10 \%$ in available PAR in the euphotic zone using national in situ investigation dataset. More importantly, the maximal loss of available PAR is recorded at the sub-surface corresponding to Chla and primary production maxima (Fig. 4b) ${ }^{[46]}$. Especially for EPL an NPL zones locating in the southeastern along 'Hu Huanyong' line, the highly synchronous significant decreases in total radiation, sunshine duration, and SDD have greatly resulted in underwater darkening of lakes (Figs. 1-3). In addition, because PAR is the main energy source of aquatic plants and $K_{\mathrm{d}}(\mathrm{PAR})$ is highly linearly correlated to ultraviolet radiation diffuse attenuation coefficient $\left(r^{2}=0.96, p<0.001, n=381\right)$ (Fig. S5), we have therefore not focused on the effects of the spectral composition of light on ecosystems. Actually, ultraviolet radiation (UVR) reaching the Earth surface over China significantly decreased markedly from 1961 to $2014^{[47]}$, and significant declines in UVR penetration and exposure were widely observed due to browning ${ }^{[48]}$.

Meanwhile, long-term SDD measurements and remote sensing studies have indicated that water clarity is decreasing in various aquatic ecosystems, including the coastal waters, estuaries, and lakes, due to human activities and climate change ${ }^{[18,19,22,28,49]}$ (Fig. 5 and Table S3). For example, a 20-year comprehensive SDD dataset assembled from Landsat imagery covering more than 10,500 lakes from 1985 to 2005 indicated SDD remained stable in central and northern 
Minnesota but decreasing SDD trends were detected in other ecoregions in southern Minnesota ${ }^{\text {[22] }}$.

Extensive browning due to rising dissolved organic matter was reported to significantly decrease SDD in the boreal lakes ${ }^{[48,50,51]}$. Therefore, underwater darkening due to decreasing water clarity in aquatic ecosystems are global environmental problems which are accentuated in China due to the high levels of air and water pollution. In comparison, water pollution makes a more important contribution to underwater darkening of China's lakes than air pollution $(9.60 \% v s 2.25 \%$ loss of average PAR in the $10 \%$ light penetration water column).

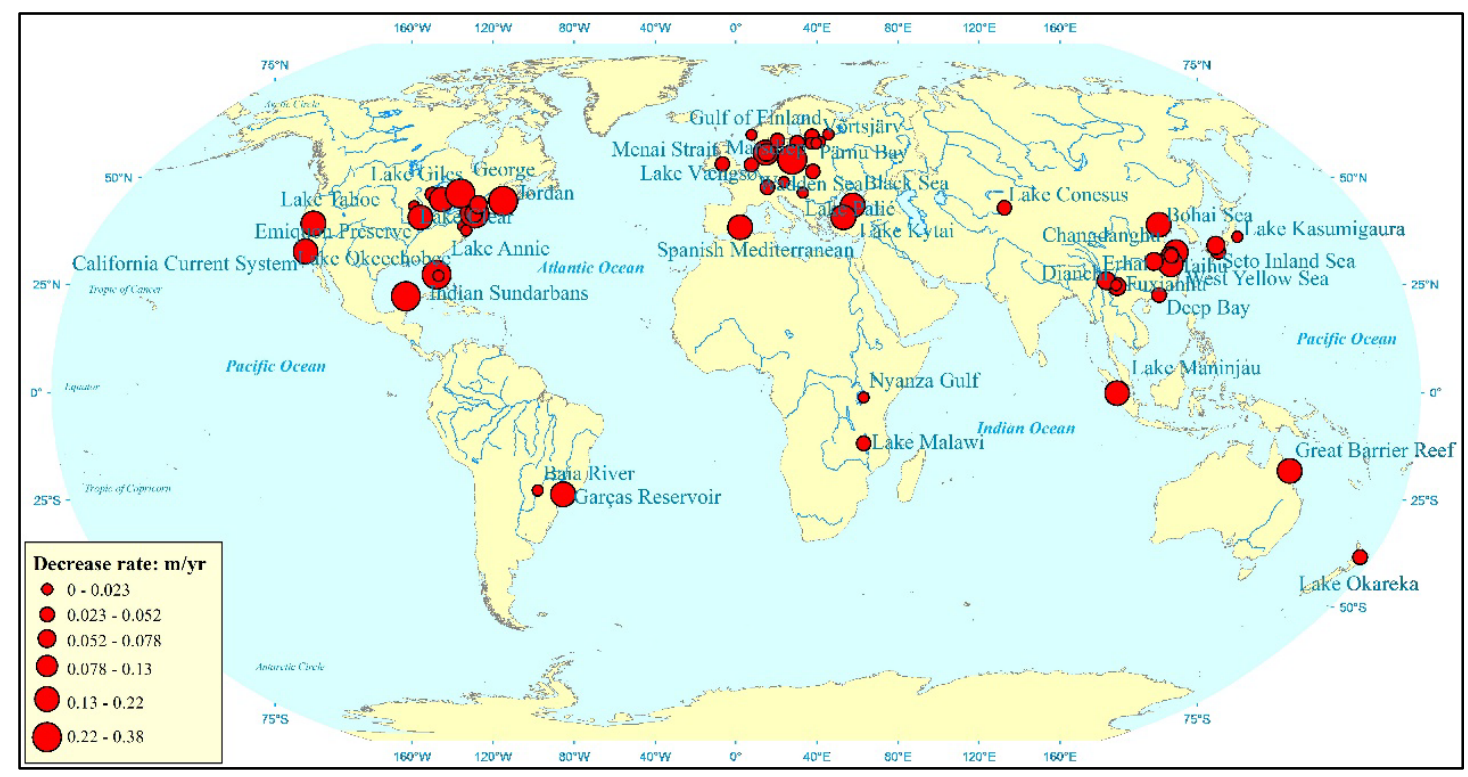

Fig. 5. Map of the world showing the significant SDD decreases, derived from long-term observations in many oceanic, coastal and inland waters in $1896-2019$. Detailed information on the literature sources is listed in Table S3.

To tackle the nation's water pollution crisis and improve freshwater habitats, China's Central government launched a "Water Pollution Prevention and Control Action Plan" (10-Point Water Plan) in April 2015. The goal is for SDD to increase with implementation of this plan, however, recent climate change model scenarios and observations suggest that extreme rainfall events and storms may increase during this century ${ }^{[52,53]}$. If that happens, turbidity due to elevated riverine discharge, 
sediment resuspension, and bottom and lakeshore erosion may increase in the future. Such events will lead to higher concentrations of suspended inorganic solids and dissolved organic matter in the

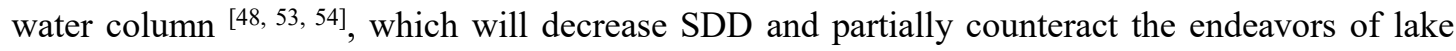
water clarity improvement.

\section{Potential effects of underwater darkening on the aquatic ecosystems}

The combined effect of radiation dimming and significant decreases in water clarity in China's lakes will undoubtedly increase underwater darkening, accelerate the deterioration of underwater light availability, and could reduce macrophyte biomass and primary production; all of which could strongly influence regional carbon and nutrient cycling. Our study demonstrated that the mean euphotic depth had decreased from $5.69 \mathrm{~m}$ before 1995 to only $4.08 \mathrm{~m}$ after 2005 in China, a decrease of approximately $1.50 \mathrm{~m}$ based on the national in situ investigation dataset. This change has been accompanied by a decrease in the maximum depth of macrophyte colonization ${ }^{[55]}$. Combining SDD and aquatic vegetation datasets in our previous study, an average $35.6 \%$ decrease of SDD resulted in an average $62.2 \%$ decrease of aquatic vegetation in 31 China's lakes ${ }^{[56]}$. Therefore, in the past three decades, the accelerating loss of macrophyte in China's lakes is tightly linked to lake underwater darkening ${ }^{[5,56]}$, similar to the situation in Lake Apopka (Florida, USA)

[17]. However, our understanding of the driving mechanisms of lake underwater darkening on ecosystem evolution will be strengthened by further study by incorporating phytoplankton biomass and macrophyte cover changes with SDD change using data from historical investigations and remote sensing.

Although many studies have documented the effects of global warming on aquatic ecosystems around the world ${ }^{[57-59]}$, no previous study has examined the effects of underwater darkening 
considering both radiation dimming and decreasing water clarity. Undoubtedly, underwater darkening will cause the reduced water quality for potable water supplies and recreational demand $[27,29,60]$. Improved water clarity was associated with increased numbers of visits to lakes and lake users were willing to incur greater costs to visit clearer lakes ${ }^{[29]}$. In addition, underwater darkening has many negative effects on the aquatic ecosystems. In aquatic ecosystems, the primary production of microalgae, macrophyte, and benthic algae is usually limited by light penetration and availability, and less by other factors such as nutrients ${ }^{[14,28,55]}$. Similarly, phytoplankton primary production and fish production have been linked to underwater light availability ${ }^{[14]}$. In addition, aquatic macrophyte biomass and species richness decrease with decreasing SDD because of lower underwater light availability ${ }^{[16,61,62]}$. Phytoplankton production and carbon fixation are positively correlated with underwater light availability, euphotic depth, and sunshine duration ${ }^{[15,63]}$. Underwater darkening, due to radiation dimming, decreasing sunshine duration, and water clarity, causes decreases in euphotic depth and underwater light availability, and could greatly contribute to decreases in macrophyte and benthic algal primary production ${ }^{[17,64,65]}$ (Fig. 6). Therefore, underwater darkening potentially could impact phytoplankton and macrophyte production, $\mathrm{CO}_{2}$ fluxes, fishery production, biodiversity and ecosystem services $[18,28,61,65,66]$ (Fig. 6). Meanwhile, it is noteworthy that phytoplankton biomass increase and algal bloom around the water surface caused by eutrophication may partially compensate the decrease of phytoplankton primary production due to underwater darkening. However, for most unproductive natural lakes worldwide, nutrients input associated with terrestrial organic matter often causes the increase of underwater light attenuation and associated benthic production (light-limited) decrease, which may override possible positive effects of nutrients increase on pelagic production (nutrient-limited) ${ }^{[14,50]}$. Similarly, if the substances 
reducing water clarity adsorb a greater proportion of UV in the surface layer then photo-inhibition may also be reduced which may compensate for some loss of light availability. Therefore, more study is needed to elucidate the interactive effects of eutrophication and underwater darkening on aquatic ecosystems.
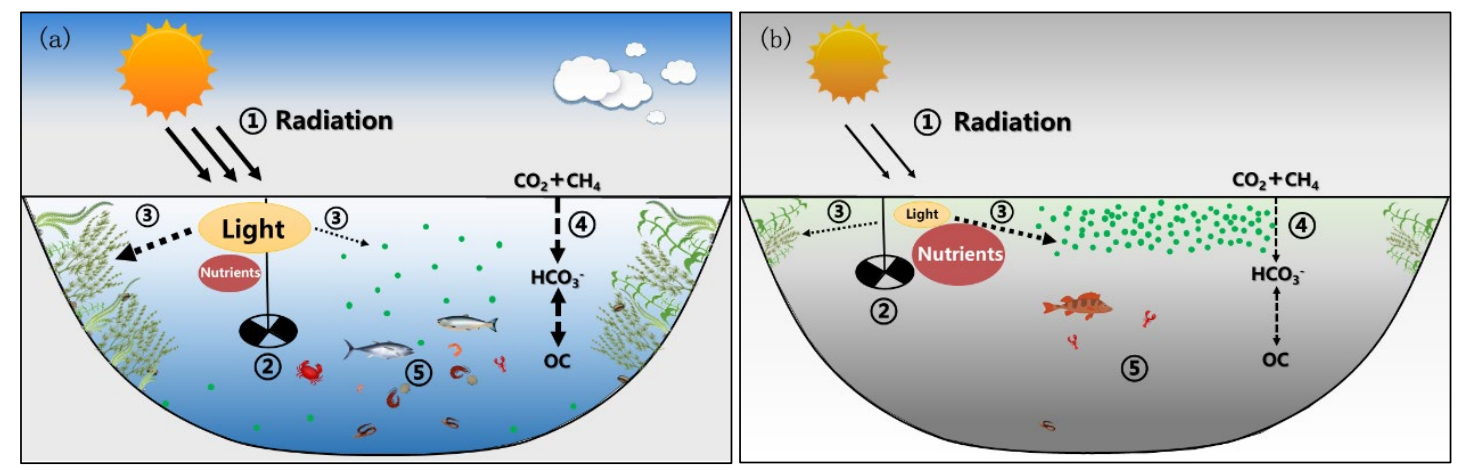

Fig. 6 Underwater darkening causes and potential effects on aquatic ecosystems in multiple ways.

(a) Scenario before 1995, (b) Scenario after 1995.

(1) Radiation dimming causes total radiation decrease reaching the water surface; (2) Water clarity decrease causes euphotic depth and underwater radiation decrease; (3) Underwater darkening will result in macrophyte, benthic algal loss, and the decrease of benthic primary production which may override possible positive effects of nutrients increase associated with underwater darkening on pelagic production; (4) Decreased benthic algal primary production and macrophyte loss may decrease carbon dioxide utilization and organic carbon fixation; (5) Underwater darkening may result in fishery production and biodiversity decreases and ecosystem services loss.

In conclusions, this study documents that radiation dimming, decreasing sunshine duration, and decreasing water clarity have altogether led to accelerating underwater darkening. Decreased water clarity plays a more important role in underwater darkening than does radiation dimming in aquatic ecosystems. This could affect many vital ecological and economic issues, such as phytoplankton and aquatic vegetation production, fishery production, and biodiversity. 


\section{Acknowledgments}

This study was jointly funded by the National Natural Science Foundation of China (grants 41621002, 41790423 and 41930760), the Key Research Program of Frontier Sciences of the Chinese Academy of Sciences (QYZDB-SSW-DQC016), the Key Program of the Chinese Academy of Sciences (ZDRW-ZS-2017-3-4), and NIGLAS Foundation (NIGLAS2017GH03 and NIGLAS2017QD08). We would like to thank our all colleagues attending the second national lake investigation, Hans Paerl, Karl Havens, and Chengfeng Le for their helpful comments and suggestions for the improvement of quality of this paper. We would like to express our gratitude to the two anonymous reviewers for their critical comments and constructive suggestions.

\section{Supplementary materials}

Fig. S1 Spatial distribution of 839 sunshine stations and 116 radiation stations in China

Fig. S2 Spatial distribution of long-term trends of total radiation at 116 observation stations in China for 1961-2013. The numerical values represent the station numbers listed in Table S1. The red circles represent a linear fitting slope greater than 0 , and the blue squares represent a linear fitting slope less than 0 . The hollows in the circles and squares indicate that the linear fitting is significant $(p<$ 0.05). Changes were significant for 49 of 90 stations with slope $<0$, and for 5 of 26 stations with slope $>0$. Different background color represents five geographic lake zones.

Fig. S3. Long-term trend of yearly mean sunshine duration at 839 stations in China.

Fig. S4. Long-term decreases of SDD from four typical lakes: (a) Lake Fuxianhu, very clear oligotrophic deep lake; (b) Lake Qiandaohu, very clear oligotrophic- mesotrophic deep reservoir; (c) Lake Erhai, moderately clear mesotrophic deep lake; (d) Lake Gehu, highly turbid eutrophic 
shallow lake.

Fig. S5. Correlation between UVR and PAR diffuse attenuation coefficients

Table S1. Detailed information on the 116 sampling stations (province, number, name, code, and altitude), and linear fitting results of yearly total radiation vs year, and the observation period.

Table S2. Detailed information on 170 lakes (zones, province, number, name, latitude, longitude, lake area, mean water depth), the SDD from two different periods (before 1995 [most before 1990] and after 2000), and the percentage change between them (comparing after 2005 with before 1995); a decrease is shown by a downward arrow.

Table S3. Summary of linear fitting, statistical parameters from 61 long-term observations of decreasing SDD, from published literature $(n=54)$ and from the present study $(n=7)$.

\section{Data availability}

The data that support the findings of this study will be open once this manuscript is accepted for publication.

\section{Author contributions}

Y.L.Z., B.Q.Q and K.S. designed the study. Y.L.Z., K.S., Y.B.Z., J.M.D., Q.F.H., Y.Q.Z., X.L.Y., M.L., G.W.Z., and L.Z. conducted the experiments and collected, analysed the data. Y.L.Z. wrote the main manuscript text. B.Q.Q., M.W., L.L., B.H.G. and J.D.B. contributed to analyzing the data and writing and editing the manuscript. All authors discussed the results and contributed to manuscript editing.

Competing financial interests: The authors declare no competing financial interests. 


\section{References:}

[1] Wild M, Gilgen H, Roesch A, et al. From dimming to brightening: Decadal changes in solar radiation at earth's surface. Science, 2005, 308: 847-850

[2] Roderick ML. The ever-flickering light. Trends in Ecology \& Evolution, 2006, 21: 3-5

[3] Mercado LM, Bellouin N, Sitch S, et al. Impact of changes in diffuse radiation on the global land carbon sink. Nature, 2009, 458: 1014-1018

[4] Wang K, Dickinson RE. Contribution of solar radiation to decadal temperature variability over land. Proceedings of the National Academy of Sciences of the United States of America, 2013, 110: 1487714882

[5] Schiermeier Q. Cleaner skies leave global warming forecasts uncertain. Nature, 2005, 435: 135135

[6] Qian Y, Wang W, Leung LR, et al. Variability of solar radiation under cloud-free skies in china: The role of aerosols. Geophysical Research Letters, 2007, 34: 2111-2121

[7] Wang K, Dickinson R, Wild M, et al. Atmospheric impacts on climatic variability of surface incident solar radiation. Atmospheric Chemistry and Physics, 2012, 12: 9581-9592

[8] Yang S, Wang XL, Wild M. Homogenization and trend analysis of the 1958-2016 in-situ surface solar radiation records in china. Journal of Climate, 2018, 31: 4529-4541

[9] Wild M. Global dimming and brightening: A review. Journal of Geophysical Research Atmospheres, 2009, 114: D00D16

[10] Wild M, Trüssel B, Ohmura A, et al. Global dimming and brightening: An update beyond 2000. Journal of Geophysical Research Atmospheres, 2009, 114: 895-896

[11] Wild M, Ohmura A, Schär C, et al. The global energy balance archive (GEBA) version 2017: A 
database for worldwide measured surface energy fluxes. Earth System Science Data, 2017, 9: 601-613

[12] Wang J, Dong J, Yi Y, et al. Decreasing net primary production due to drought and slight decreases in solar radiation in china from 2000 to 2012. Journal of Geophysical Research: Biogeosciences, 2017, 122: $261-278$

[13] Williamson CE, Zepp RG, Lucas RM, et al. Solar ultraviolet radiation in a changing climate. Nature Climate Change, 2014, 4: 434-441

[14] Karlsson J, Byström P, Ask J, et al. Light limitation of nutrient-poor lake ecosystems. Nature, 2009, 460: 506-509

[15] Behrenfeld MJ, Falkowski PG. Photosynthetic rates derived from satellite-based chlorophyll concentration. Limnology and Oceanography, 1997, 42: 1-20

[16] Havens KE. Submerged aquatic vegetation correlations with depth and light attenuating materials in a shallow subtropical lake. Hydrobiologia, 2003, 493: 173-186

[17] Schelske CL, Lowe EF, Kenney WF, et al. How anthropogenic darkening of lake apopka induced benthic light limitation and forced the shift from macrophyte to phytoplankton dominance. Limnology and Oceanography, 2010, 55: 1201-1212

[18] Capuzzo E, Stephens D, Silva T, et al. Decrease in water clarity of the southern and central North Sea during the 20th century. Global Change Biology, 2015, 21: 2206-2214

[19] Lefcheck JS, Wilcox DJ, Murphy RR, et al. Multiple stressors threaten the imperiled coastal foundation species eelgrass (Zostera marina) in Chesapeake Bay, USA. Global Change Biology, 2017, 23: 3474-3483

[20] Preisendorfer RW. Secchi disk science: Visual optics of natural waters. Limnology and Oceanography, 1986, 31: 909-926 
[21] Ruhl HA, Rybicki NB. Long-term reductions in anthropogenic nutrients link to improvements in Chesapeake Bay habitat. Proceedings of the National Academy of Sciences of the United States of America, 2010, 107: 16566-16570

[22] Olmanson LG, Bauer ME, Brezonik PL. A 20-year Landsat water clarity census of Minnesota's 10,000 lakes. Remote Sensing of Environment, 2008, 112: 4086-4097

[23] Shi K, Zhang Y, Qin B, et al. Remote sensing of cyanobacterial blooms in inland waters: Present knowledge and future challenges. Science Bulletin, 2019, 64: 1540-1556

[24] Lee Z, Shang S, Hu C, et al. Secchi disk depth: A new theory and mechanistic model for underwater visibility. Remote Sensing of Environment, 2015, 169: 139-149

[25] Rodrigues T, Alcântara E, Watanabe F, et al. Retrieval of secchi disk depth from a reservoir using a semi-analytical scheme. Remote Sensing of Environment, 2017, 198: 213-228

[26] Vundo A, Matsushita B, Jiang D, et al. An overall evaluation of water transparency in Lake Malawi from meris data. Remote Sensing, 2019, 11:279

[27] Shi K, Zhang Y, Zhu G, et al. Deteriorating water clarity in shallow waters: Evidence from long term MODIS and in-situ observations. International journal of applied earth observation and geoinformation, 2018, 68: 287-297

[28] Boyce DG, Lewis MR, Worm B. Global phytoplankton decline over the past century. Nature, 2010, 466: $591-596$

[29] Keeler BL, Wood SA, Polasky S, et al. Recreational demand for clean water: Evidence from geotagged photographs by visitors to lakes. Frontiers in Ecology and the Environment, 2016, 13: 76-81

[30] Rose KC, Greb SR, Diebel M, et al. Annual precipitation regulates spatial and temporal drivers of lake water clarity. Ecological Applications, 2017, 27: 632-643 
[31] Wang S, Dou H. Lakes in china. Beijing: Science Press, 1998

[32] Ma R, Duan H, Hu C, et al. A half-century of changes in china's lakes: Global warming or human influence? Geophysical Research Letters, 2010, 37: doi:10.1029/2010GL045514

[33] Zhang Y, Zhou Y, Shi K, et al. Optical properties and composition changes in chromophoric dissolved organic matter along trophic gradients: Implications for monitoring and assessing lake eutrophication. Water Research, 2018, 131: 255-263

[34] Zhou Q, Zhang Y, Li K, et al. Seasonal and spatial distributions of euphotic zone and long-term variations in water transparency in a clear oligotrophic Lake Fuxian, china. Journal of Environmental Sciences, 2018, 72: 185-197

[35] Zhang Y, Wu Z, Liu M, et al. Thermal structure and response to long-term climatic changes in Lake Qiandaohu, a deep subtropical reservoir in China. Limnology and Oceanography, 2014, 59: 1193-1202 [36] Olmanson LG, Brezonik PL, Bauer ME. Evaluation of medium to low resolution satellite imagery for regional lake water quality assessments. Water Resources Research, 2011, 47: W09515, doi:09510.01029/02011WR011005

[37] Dekker A, Peters S. The use of the thematic mapper for the analysis of eutrophic lakes: A case study in the netherlands. International Journal of Remote Sensing, 1993, 14: 799-821

[38] Zhang Y, Zhang Y, Shi K, et al. Calibration and validation of a remote sensing-based model of optical water clarity for various inland lakes in China. IEEE Transactions on Geoscience and Remote Sensing, 2020,

[39] Shi K, Zhang Y, Liu X, et al. Remote sensing of diffuse attenuation coefficient of photosynthetically active radiation in Lake Taihu using MERIS data. Remote Sensing of Environment, 2014, 140: 365-377 [40] Yang Q, He L. Spatiotemporal changes in population distribution and socioeconomic development 
in China from 1950 to 2010. Arabian Journal of Geosciences, 2017, 10: 498

[41] Li X, Wagner F, Peng W, et al. Reduction of solar photovoltaic resources due to air pollution in China. Proceedings of the National Academy of Sciences of the United States of America, 2017, 114:

$11867-11872$

[42] Soni V, Pandithurai G, Pai D. Evaluation of long-term changes of solar radiation in India. International Journal of Climatology, 2012, 32: 540-551

[43] Streets DG, Yan F, Chin M, et al. Anthropogenic and natural contributions to regional trends in aerosol optical depth, 1980-2006. Journal of Geophysical Research: Atmospheres, 2009, 114:

[44] Lewis MR, Kuring N, Yentsch C. Global patterns of ocean transparency: Implications for the new production of the open ocean. Journal of Geophysical Research: Oceans, 1988, 93: 6847-6856

[45] Zhang G, Luo W, Chen W, et al. A robust but variable lake expansion on the Tibetan Plateau. Science Bulletin, 2019, 64: 1306-1309

[46] Katja F, Emmanuel B. Subsurface maxima of phytoplankton and chlorophyll: Steady-state solutions from a simple model. Limnology and Oceanography, 2003, 48: 1521-1534

[47] Liu H, Hu B, Zhang L, et al. Ultraviolet radiation over China: Spatial distribution and trends. Renewable \& Sustainable Energy Reviews, 2017, 76: 1371-1383

[48] Williamson CE, Overholt EP, Pilla RM, et al. Ecological consequences of long-term browning in lakes. Scientific Reports, 2015, 5: doi: 10.1038/srep18666

[49] Dupont N, Aksnes D. Centennial changes in water clarity of the Baltic Sea and the North Sea. Estuarine, Coastal and Shelf Science, 2013, 131: 282-289

[50] Leach TH, Winslow LA, Hayes NM, et al. Decoupled trophic responses to long-term recovery from acidification and associated browning in lakes. Global Change Biology, 2019, 25: 1779-1792 
[51] Pilla RM, Williamson CE, Jing Z, et al. Browning-related decreases in water transparency lead to long-term increases in surface water temperature and thermal stratification in two small lakes. Journal of Geophysical Research Biogeosciences, 2018, 123: 1651-1665

[52] O'Gorman PA, Schneider T. The physical basis for increases in precipitation extremes in simulations of 21st-century climate change. Proceedings of the National Academy of Sciences of the United States of America, 2009, 106: 14773-14777

[53] Zhang Y, Shi K, Zhou Y, et al. Monitoring the river plume induced by heavy rainfall events in large, shallow, Lake Taihu using modis 250 m imagery. Remote Sensing of Environment, 2016, 173: 109-121

[54] Williamson CE, Overholt EP, Brentrup JA, et al. Sentinel responses to droughts, wildfires, and floods: Effects of UV radiation on lakes and their ecosystem services. Frontiers in Ecology \& the Environment, 2016, 14: 102-109

[55] Zhang Y, Liu X, Qin B, et al. Aquatic vegetation in response to increased eutrophication and degraded light climate in eastern Lake Taihu implications for lake ecological restoration. Scientific Reports, 2016, 6: DOI: 10.1038/srep23867

[56] Zhang Y, Jeppesen E, Liu X, et al. Global loss of aquatic vegetation in lakes. Earth-Science Reviews, 2017, 173: 259-265

[57] Paerl HW, Huisman J. Climate change: A catalyst for global expansion of harmful cyanobacterial blooms. Environmental Microbiology Reports, 2009, 1: 27-37

[58] O'Beirne MD, Werne JP, Hecky RE, et al. Anthropogenic climate change has altered primary productivity in Lake Superior. Nature Communications, 2017, 8: doi: 10.1038/ncomms15713

[59] Cohen AS, Gergurich EL, Kraemer BM, et al. Climate warming reduces fish production and benthic habitat in Lake Tanganyika, one of the most biodiverse freshwater ecosystems. Proceedings of the 
National Academy of Sciences of the United States of America, 2016, 113: 9563-9568

[60] Qin B, Paerl HW, Brookes JD, et al. Why Lake Taihu continues to be plagued with cyanobacterial blooms through 10 years (2007-2017) efforts. Science Bulletin, 2019, 64: 354-356

[61] Sand-Jensen K, Pedersen NL, Thorsgaard I, et al. 100 years of vegetation decline and recovery in Lake Fure, Denmark. Journal of Ecology, 2008, 96: 260-271

[62] Scheffer M, Carpenter S, Foley JA, et al. Catastrophic shifts in ecosystems. Nature, 2001, 413: 591596

[63] Field CB, Behrenfeld MJ, Randerson JT, et al. Primary production of the biosphere: Integrating terrestrial and oceanic components. Science, 1998, 281: 237-240

[64] Waycott M, Duarte CM, Carruthers TJ, et al. Accelerating loss of seagrasses across the globe threatens coastal ecosystems. Proceedings of the National Academy of Sciences of the United States of America, 2009, 106: 12377-12381

[65] Batt RD, Carpenter SR, Cole JJ, et al. Altered energy flow in the food web of an experimentally darkened lake. Ecosphere, 2016, 6: 1-23

[66] Walsh JR, Carpenter SR, Jake Vander Zanden M. Invasive species triggers a massive loss of ecosystem services through a trophic cascade. Proceedings of the National Academy of Sciences of the United States of America, 2016, 113: 4081-4085 


\section{Supplementary Material}

\section{Radiation dimming and decreasing water clarity fuel underwater darkening in lakes}

Yunlin Zhang ${ }^{1,2^{*}}$, Boqiang Qin ${ }^{1,2^{*}}$, Kun $\mathrm{Shi}^{1,2}$, Yibo Zhang ${ }^{1,2}$, Jianming Deng ${ }^{1,2}$, Martin Wild ${ }^{3}$, Lin $\mathrm{Li}^{4}$, Yongqiang Zhou ${ }^{1,2}$, Xiaolong Yao ${ }^{1,2}$, Miao Liu ${ }^{1,2}$, Guangwei Zhu ${ }^{1,2}$, Lu Zhang ${ }^{1,2}$, Binhe Gu${ }^{5}$, Justin D. Brookes ${ }^{6}$

1 Taihu Laboratory for Lake Ecosystem Research, State Key Laboratory of Lake Science and Environment, Nanjing Institute of Geography and Limnology, Chinese Academy of Sciences, Nanjing 210008, China

2 University of Chinese Academy of Sciences, Beijing 100049, China

3 Institute for Atmospheric and Climate Science, ETH Zurich, Zurich, Switzerland

4 Department of Earth Sciences, Indiana University-Purdue University Indianapolis, $723 \mathrm{~W}$. Michigan St, SL118, Indianapolis 46202, USA

5 Soil and Water Science Department, University of Florida, Gainesville, Florida 32611, USA

6 Water Research Centre, Environment Institute, School of Biological Science, University of Adelaide, 5005 Adelaide, Australia

"Corresponding author: Yunlin Zhang, Email: ylzhang@niglas.ac.cn; Boqiang Qin, Email: qinbq@niglas.ac.cn, Nanjing Institute of Geography and Limnology, Chinese Academy of Sciences, 73 East Beijing Road, Nanjing 210008, P. R. China, Tel: +86-25-86882198, Fax: +86-25-57714759 
A standard 30-cm diameter Secchi disk was used to measure the SDD. The Secchi disk is a circular black-and-white disk that is lowered into a body of water by an observer until it disappears from view, and the depth at which it is no longer visible is recorded as the transparency. In situ SDD measurements were carried out in 170 lakes before 1995 and after 2005 from two nation-wide lake investigations and published literature, and four special lakes for more than 25 years long-term sitespecific observations. 170 lakes were distributed in five geographic lake zones in China (Fig. S2).

In addition, there were four lakes that were studied in details for the long-term (more than 25 years), site specific, in situ SDD measurement. Lake Fuxianhu $\left(24^{\circ} 21^{\prime} \sim 24^{\circ} 38^{\prime} \mathrm{N}\right.$, $102^{\circ} 49^{\prime} \sim 102^{\circ} 57^{\prime} \mathrm{E}$; Fig. 1) is a warm fault lake located in the middle of the Yungui Plateau in southwestern China (Yuxi City, Yunnan Province). Lake Fuxianhu is characterized by a central subtropical, plateau, semi-humid, monsoon climate. This lake has a water area of $211.0 \mathrm{~km}^{2}$, a mean depth of $89.6 \mathrm{~m}$, a maximum depth of $155.0 \mathrm{~m}$, and a water storage of $189.0 \times 10^{8} \mathrm{~m}^{3}$ at a water level of $1771.0 \mathrm{~m}$. Lake Fuxianhu is a clear oligotrophic deep lake with a mean SDD of $6.20 \mathrm{~m}$ (1).

Lake Qiandaohu $\left(29^{\circ} 22^{\prime}-29^{\circ} 50^{\prime} \mathrm{N}, 118^{\circ} 36^{\prime}-119^{\circ} 14^{\prime} \mathrm{E}\right)$ was originally called Xin'anjiang Reservoir and is located in western Zhejiang Province and southern Anhui Province. Lake Qiandaohu has a water area of $580 \mathrm{~km}^{2}$, an average depth of $30 \mathrm{~m}$, a water volume of $178.4 \times 10^{8} \mathrm{~m}^{3}$, and a basin area of $10,480 \mathrm{~km}^{2}$ when the water level is $108 \mathrm{~m}$. Lake Qiandaohu is a clear oligotrophic - mesotrophic deep lake with the mean SDD of $6.39 \mathrm{~m}(2)$.

Lake Erhai $\left(25^{\circ} 35^{\prime}-25^{\circ} 58^{\prime} \mathrm{N}, 100^{\circ} 5^{\prime}-100^{\circ} 17^{\prime} \mathrm{E}\right)$ is located in Yunnan Province, Southwest China. The lake has a water area of $249.8 \mathrm{~km}^{2}$, a mean water depth of $10.5 \mathrm{~m}$ and a maximal depth of $21.0 \mathrm{~m}$. Lake Erhai is a medium clear mesotrophic deep lake with the mean SDD of $2.75 \mathrm{~m}$.

Lake Gehu $\left(30^{\circ} 28^{\prime}-31^{\circ} 42^{\prime} \mathrm{N}\right.$ and $\left.119^{\circ} 44^{\prime}-119^{\circ} 53^{\prime} \mathrm{E}\right)$ is a large freshwater lake in China, which 
is located in the Yangtze River Delta and has a water area of $146.5 \mathrm{~km}^{2}$, a mean depth of $1.2 \mathrm{~m}$. As a typical eutrophic shallow lake, Lake Gehu has experienced serious lake eutrophication, algal blooms and water quality deterioration in the past 30 years.

The Eastern Plain Lake (EPL) zone covers the municipalities of Beijing, Shanghai, and Tianjin; the provinces of Anhui, Fujian, Guangdong, Guangxi, Hainan, Henan, Hubei, Hunan, Jiangsu, Jiangxi, Shandong, Taiwan, and Zhejiang; and the Special Administrative Regions of Hong Kong and Macao. The Yunnan-Guizhou Plateau Lake (YGPL) zone covers the municipality of Chongqing and the provinces of Yunnan, Guizhou and Sichuan. The Northeast Plain Lake (NPL) zone covers the provinces of Liaoning, Jilin and Heilongjiang. The Inner Mongolia-Xinjiang Lake (IMXL) zone covers the provinces of Gansu, Shaanxi and Shanxi and autonomous regions of Inner Mongolia, Xinjiang Uygur and Ningxia Hui. The Tibetan Plateau Lake (TPL) zone covers Qinghai Province and Tibet Autonomous Region. The total number of lakes with areas $>1 \mathrm{~km}^{2}$ in the fives zones were: EPL 634, YGPL 65, NPL 425, IMXL 514, and TPL 1055 (3). 


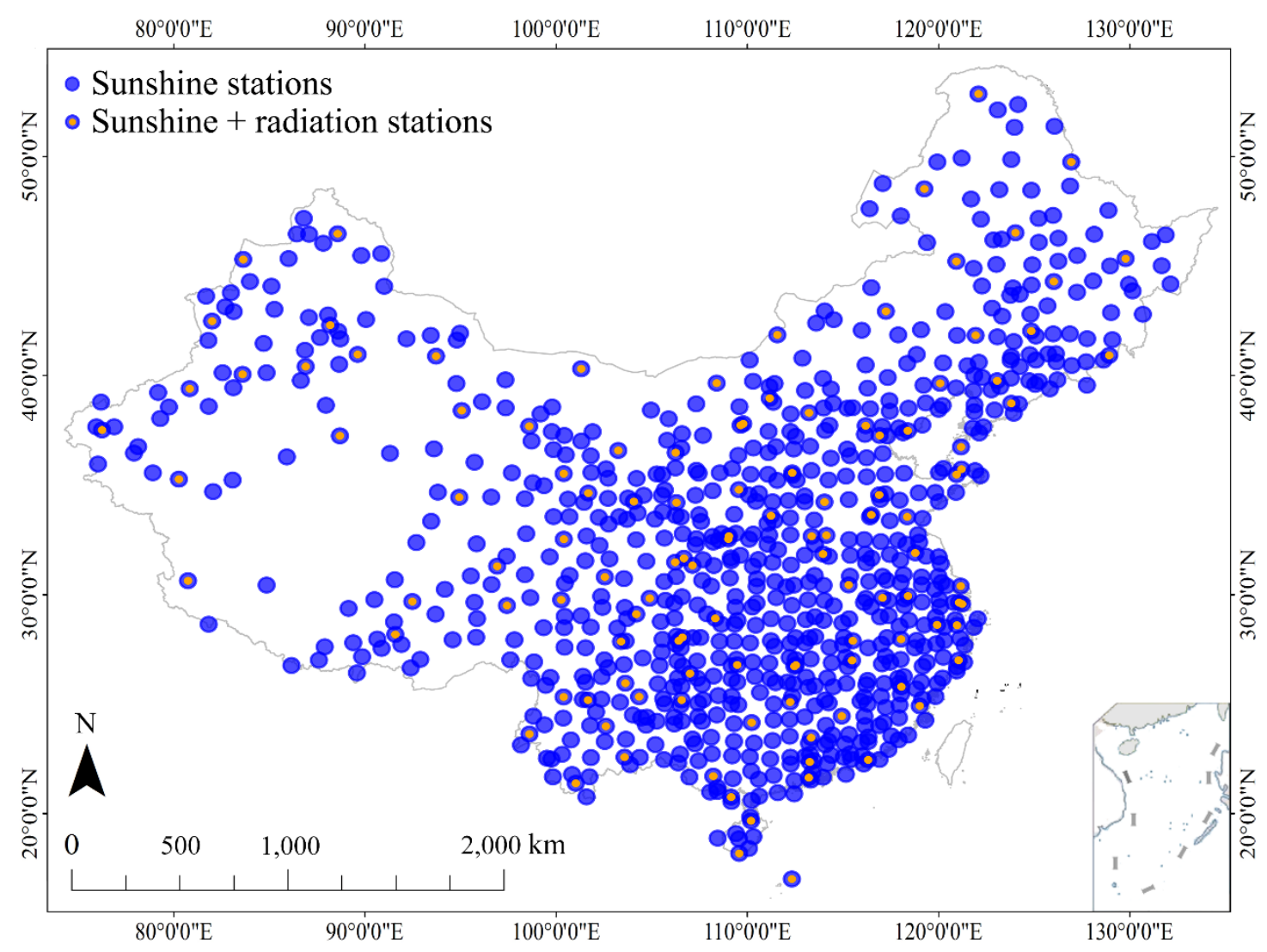

Fig. S1 Spatial distribution of 839 sunshine stations and 116 radiation stations in China 


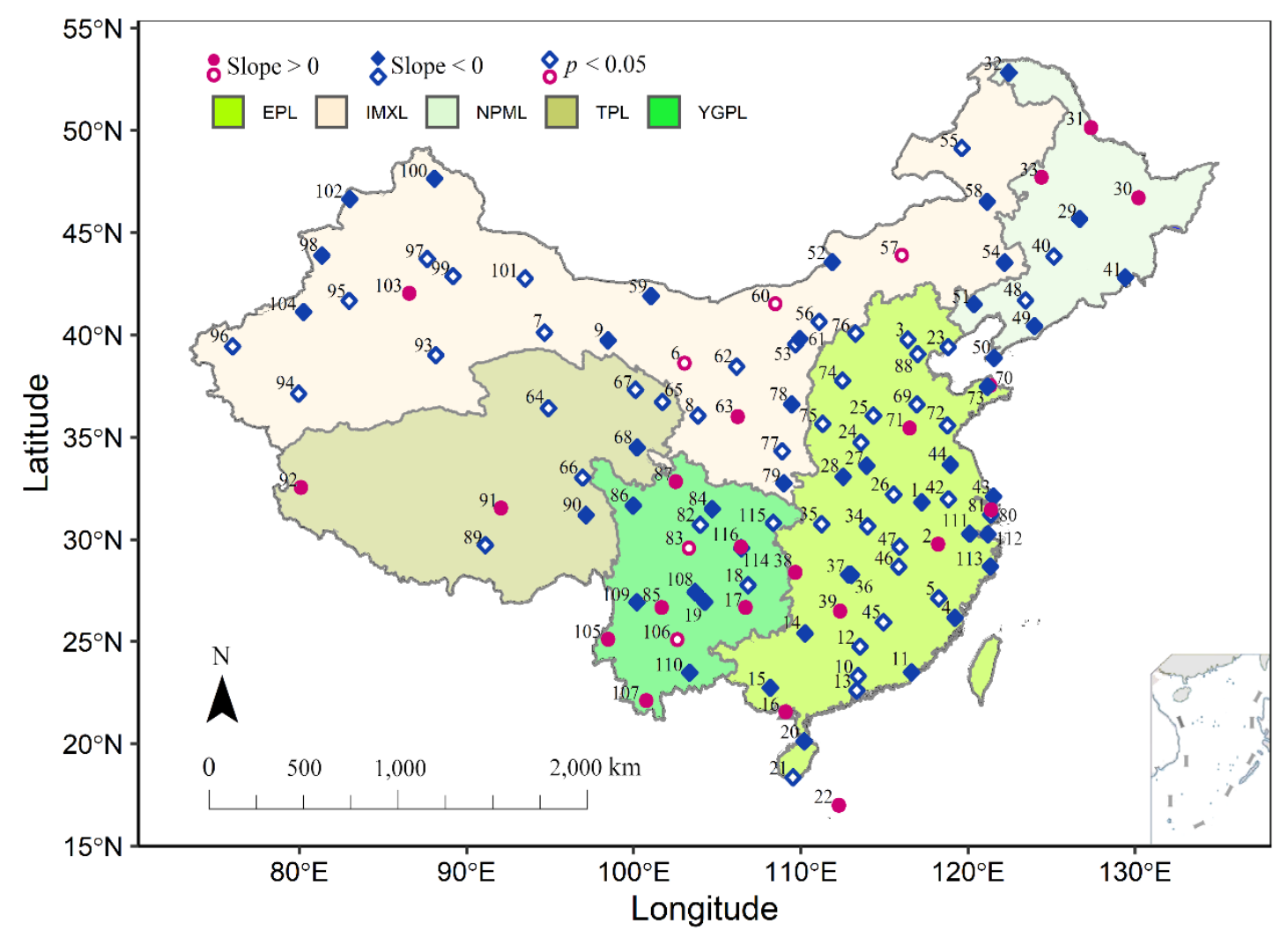

Fig. S2. Spatial distribution of long-term trends of total radiation at 116 observation stations in

China for 1961-2013. The numerical values represent the station numbers listed in Table S1. The red circles represent a linear fitting slope greater than 0 , and the blue squares represent a linear fitting slope less than 0 . The hollows in the circles and squares indicate that the linear fitting is significant $(p<0.05)$. Changes were significant for 49 of 90 stations with slope $<0$, and for 5 of 26 stations with slope $>0$. Different background color represents five geographic lake zones.

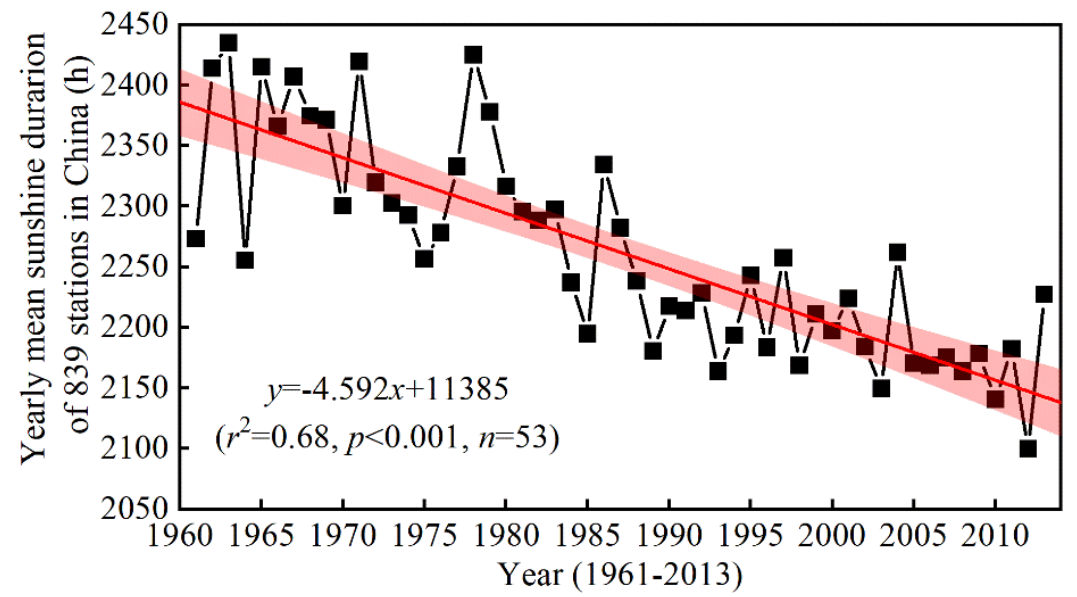

Fig. S3. Long-term trend of yearly mean sunshine duration at 839 stations in China. 

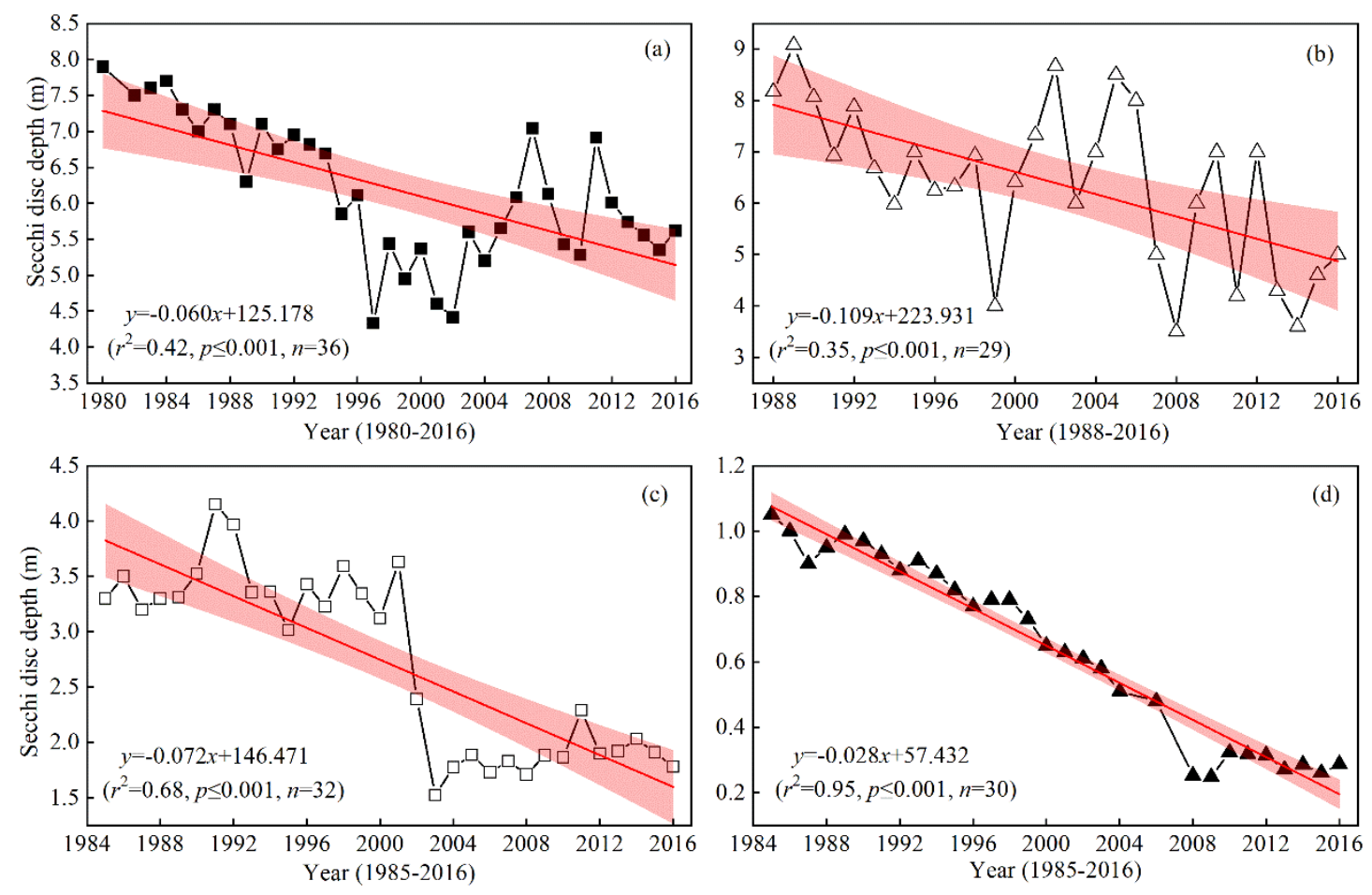

Fig. S4. Long-term decreases of SDD from four typical lakes: (a) Lake Fuxianhu, very clear

oligotrophic deep lake; (b) Lake Qiandaohu, very clear oligotrophic- mesotrophic deep reservoir;

(c) Lake Erhai, moderately clear mesotrophic deep lake; (d) Lake Gehu, highly turbid eutrophic shallow lake.

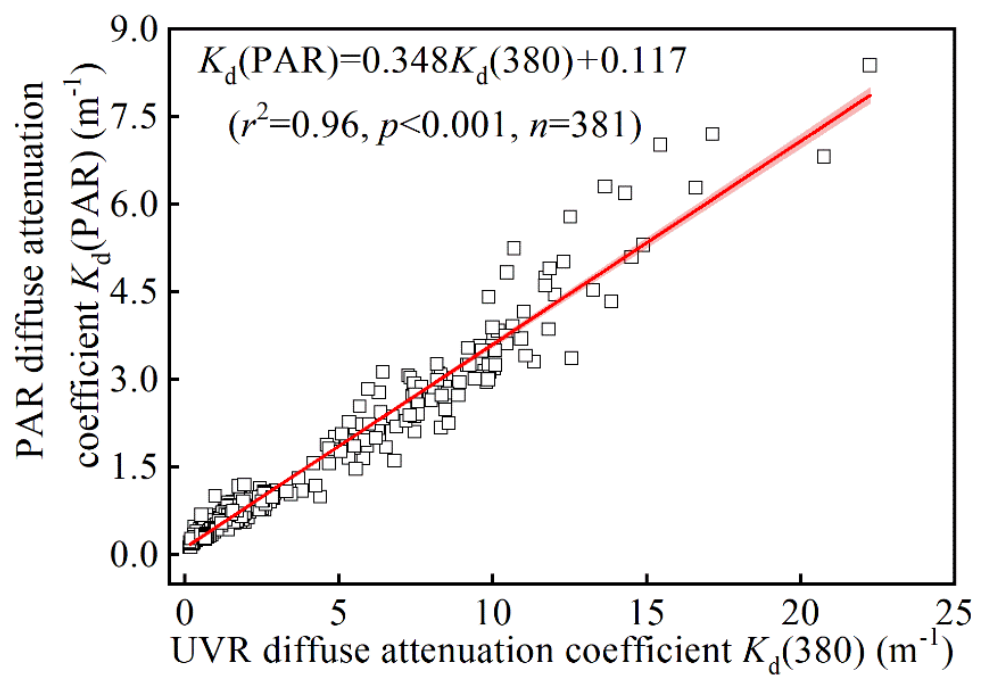

Fig. S5 Correlation between UVR and PAR diffuse attenuation coefficients 
Table S1. Detailed information on the 116 sampling stations (province, number, name, code, and altitude), and linear fitting results of yearly total radiation $v s$ year, and the observation period.

\begin{tabular}{|c|c|c|c|c|c|c|c|c|c|c|}
\hline Province & Number & Station name & Station code & Altitude & Linear slope & $r^{2}$ & $p$ & $n$ & Trend & Observation perioc \\
\hline & 1 & Heifei & 58321 & 27 & -651.69 & 0.053 & 0.098 & 53 & Decrease & $1961-2013$ \\
\hline \multicolumn{11}{|l|}{ Anhui } \\
\hline & 2 & Tunxi & 58531 & 142.7 & 1161.43 & 0.130 & 0.099 & 22 & Increase & $1992-2013$ \\
\hline Beijing & 3 & Beijing & 54511 & 31.3 & -2233.18 & 0.622 & 0.000 & 53 & Significant decrease & $1961-2013$ \\
\hline & 4 & Fuzhou & 58847 & 84 & -249.23 & 0.012 & 0.427 & 53 & Decrease & $1961-2013$ \\
\hline \multicolumn{11}{|l|}{ Fujian } \\
\hline & 5 & Jianou & 58737 & 154.9 & -3916.79 & 0.225 & 0.026 & 22 & Significant decrease & $1992-2013$ \\
\hline & 6 & Minqin & 52681 & 1367.5 & 746.69 & 0.078 & 0.043 & 53 & Significant decrease & $1961-2013$ \\
\hline & 7 & Dunhuang & 52418 & 1139 & -691.76 & 0.124 & 0.010 & 53 & Significant decrease & $1961-2013$ \\
\hline \multicolumn{11}{|l|}{ Gansu } \\
\hline & 8 & Lanzhou & 52889 & 1517.2 & -1494.55 & 0.227 & 0.001 & 44 & Significant decrease & 1961-2004 \\
\hline & 9 & Jiuquan & 52533 & 1477.2 & -301.45 & 0.014 & 0.613 & 21 & Decrease & $1993-2013$ \\
\hline Guangdong & 10 & Guangzhou & 59287 & 70.7 & -783.95 & 0.101 & 0.021 & 53 & Significant decrease & $1961-2013$ \\
\hline
\end{tabular}




\begin{tabular}{|c|c|c|c|c|c|c|c|c|c|c|}
\hline & 11 & Shantou & 59316 & 2.9 & -239.32 & 0.007 & 0.564 & 53 & Decrease & $1961-2013$ \\
\hline & 12 & Shaoguang & 59082 & 121.3 & -4490.88 & 0.599 & 0.000 & 30 & Significant decrease & $1961-1990$ \\
\hline & 13 & Zhongshan & 59485 & 33.7 & -6847.23 & 0.474 & 0.000 & 26 & Significant decrease & $1965-1990$ \\
\hline & 14 & Guilin & 57957 & 164.4 & -621.01 & 0.050 & 0.108 & 53 & Decrease & $1961-2013$ \\
\hline \multirow[t]{3}{*}{ Guangxi } & 15 & Nanning & 59431 & 121.6 & -277.90 & 0.016 & 0.365 & 53 & Decrease & $1961-2013$ \\
\hline & 16 & Beihai & 59644 & 12.8 & 507.95 & 0.024 & 0.505 & 21 & Increase & 1993-2013 \\
\hline & 17 & Guiyang & 57816 & 1223.8 & 14.97 & 0.000 & 0.966 & 53 & Increase & $1961-2013$ \\
\hline \multirow[t]{3}{*}{ Guizhou } & 18 & Zunyi & 57713 & 843.9 & -3165.40 & 0.492 & 0.000 & 30 & Significant decrease & $1961-1990$ \\
\hline & 19 & Weining & 56691 & 2237.5 & -602.60 & 0.043 & 0.269 & 30 & Decrease & $1961-1990$ \\
\hline & 20 & Haikou & 59758 & 63.5 & -342.22 & 0.015 & 0.380 & 53 & Decrease & $1961-2013$ \\
\hline \multirow[t]{2}{*}{ Hainan } & 21 & Sanya & 59948 & 419.4 & -1867.44 & 0.249 & 0.018 & 22 & Significant decrease & $1992-2013$ \\
\hline & 22 & Xisha & 59981 & 4.7 & 479.51 & 0.004 & 0.770 & 22 & Increase & $1992-2013$ \\
\hline Hebei & 23 & Leting & 54539 & 10.5 & -1889.37 & 0.363 & 0.003 & 22 & Significant decrease & $1992-2013$ \\
\hline
\end{tabular}




\begin{tabular}{|c|c|c|c|c|c|c|c|c|c|c|}
\hline & 24 & Zhengzhou & 57083 & 110.4 & -641.83 & 0.095 & 0.024 & 53 & Significant decrease & $1961-2013$ \\
\hline & 25 & Anyang & 53898 & 62.9 & -1510.73 & 0.149 & 0.035 & 30 & Significant decrease & $1961-1990$ \\
\hline \multirow[t]{5}{*}{ Henan } & 26 & Gushi & 58208 & 42.9 & -1839.18 & 0.272 & 0.000 & 53 & Significant decrease & $1961-2013$ \\
\hline & 27 & Yancheng & 57186 & 60.8 & -2591.79 & 0.099 & 0.090 & 30 & Decrease & $1961-1990$ \\
\hline & 28 & Nanyang & 57178 & 129.2 & -557.82 & 0.042 & 0.338 & 24 & Decrease & $1990-2013$ \\
\hline & 29 & Haerbin & 50953 & 142.3 & -171.18 & 0.007 & 0.542 & 53 & Decrease & $1961-2013$ \\
\hline & 30 & Jiamusi & 50873 & 82 & 137.26 & 0.004 & 0.658 & 53 & Increase & $1961-2013$ \\
\hline \multirow[t]{4}{*}{ Heilongjiang } & 31 & Hehei & 50468 & 166.4 & 357.70 & 0.022 & 0.292 & 53 & Increase & $1961-2013$ \\
\hline & 32 & Mohe & 50136 & 433 & -552.87 & 0.009 & 0.689 & 21 & Decrease & 1993-2013 \\
\hline & 33 & Fuyu & 50742 & 162.7 & 319.94 & 0.008 & 0.696 & 21 & Increase & 1993-2013 \\
\hline & 34 & Wuhan & 57494 & 23.6 & -1890.25 & 0.234 & 0.000 & 53 & Significant decrease & $1961-2013$ \\
\hline \multicolumn{11}{|l|}{ Hubei } \\
\hline & 35 & Yichang & 57461 & 133.1 & -705.76 & 0.086 & 0.034 & 53 & Significant decrease & $1961-2013$ \\
\hline Hunan & 36 & Chanshal & 57679 & 44.9 & -3128.41 & 0.403 & 0.000 & 26 & Significant decrease & $1961-1986$ \\
\hline
\end{tabular}




\begin{tabular}{|c|c|c|c|c|c|c|c|c|c|c|}
\hline & 37 & Changsha2 & 57687 & 68 & -101.67 & 0.001 & 0.899 & 27 & Decrease & $1987-2013$ \\
\hline & 38 & Jishou & 57649 & 208.4 & 718.75 & 0.026 & 0.475 & 22 & Increase & $1992-2013$ \\
\hline & 39 & Changning & 57874 & 116.6 & 3554.58 & 0.099 & 0.153 & 22 & Increase & $1992-2013$ \\
\hline \multirow{3}{*}{ Jilin } & 41 & Changchun & 54161 & 236.8 & -568.37 & 0.084 & 0.036 & 53 & Significant decrease & $1961-2013$ \\
\hline & & & & & & & & & & \\
\hline & 42 & Yanji & 54292 & 257.3 & -75.11 & 0.001 & 0.789 & 53 & Decrease & $1961-2013$ \\
\hline \multirow{3}{*}{ Jiangsu } & 40 & Huaian & 58141 & 14.4 & -1597.45 & 0.133 & 0.114 & 21 & Decrease & 1993-2013 \\
\hline & 43 & Nanjing & 58238 & 35.2 & -981.34 & 0.140 & 0.006 & 53 & Significant decrease & $1961-2013$ \\
\hline & 44 & Lvsi & 58265 & 3.6 & -1238.87 & 0.074 & 0.222 & 22 & Decrease & $1992-2013$ \\
\hline \multirow{3}{*}{ Jiangxi } & 45 & Ganzhou & 57993 & 133.1 & -856.22 & 0.172 & 0.002 & 53 & Significant decrease & $1961-2013$ \\
\hline & 46 & Nanchang & 58606 & 46.9 & -1491.25 & 0.292 & 0.000 & 53 & Significant decrease & $1961-2013$ \\
\hline & 47 & Lushan & 58506 & 1164.5 & -5646.62 & 0.506 & 0.000 & 30 & Significant decrease & $1961-1990$ \\
\hline \multirow{2}{*}{ Liaoning } & 48 & Shenyang & 54342 & 49 & -783.86 & 0.130 & 0.008 & 53 & Significant decrease & $1961-2013$ \\
\hline & 49 & Fengcheng & 54494 & 72.6 & -771.98 & 0.009 & 0.627 & 30 & Decrease & $1961-1990$ \\
\hline
\end{tabular}




\begin{tabular}{|c|c|c|c|c|c|c|c|c|c|c|}
\hline & 50 & Dalian & 54662 & 91.5 & -210.90 & 0.004 & 0.649 & 53 & Decrease & $1963-2013$ \\
\hline & 51 & Chaoyang & 54324 & 174.3 & -57.06 & 0.001 & 0.861 & 53 & Decrease & $1963-2013$ \\
\hline & 52 & Erlianghaote & 53068 & 963.1 & -115.27 & 0.004 & 0.652 & 53 & Decrease & $1961-2013$ \\
\hline & 53 & Yijinhuoluoqi & 53545 & 1329.3 & -1921.76 & 0.180 & 0.017 & 31 & Significant decrease & 1961-1991 \\
\hline & 54 & Tongliao & 54135 & 178.7 & -214.21 & 0.005 & 0.627 & 53 & Decrease & $1961-2013$ \\
\hline & 55 & Hailaer & 50527 & 649.6 & -1032.85 & 0.355 & 0.000 & 53 & Significant decrease & $1961-2013$ \\
\hline Inner & 56 & Tumotezuoqi & 53464 & 1020.3 & -6950.26 & 0.687 & 0.000 & 21 & Significant decrease & 1971-1991 \\
\hline \multirow[t]{5}{*}{ Mongolia } & 57 & Xilinhaote & 54102 & 1003 & 1484.29 & 0.246 & 0.014 & 24 & Significant increase & $1990-2013$ \\
\hline & 58 & Suolun & 50834 & 499.7 & -1075.68 & 0.058 & 0.278 & 22 & Decrease & $1992-2013$ \\
\hline & 59 & Ejinaqi & 52267 & 940.5 & -468.57 & 0.055 & 0.294 & 22 & Decrease & $1992-2013$ \\
\hline & 60 & Hailiutu & 53336 & 1288 & 4179.78 & 0.314 & 0.007 & 22 & Significant increase & $1992-2013$ \\
\hline & 61 & Dongsheng & 53543 & 1461.9 & -734.41 & 0.060 & 0.272 & 22 & Decrease & $1992-2013$ \\
\hline Ningxia & 62 & Yinchuan & 53614 & 1110.9 & -1046.72 & 0.433 & 0.000 & 53 & Significant decrease & $1961-2013$ \\
\hline
\end{tabular}




\begin{tabular}{|c|c|c|c|c|c|c|c|c|c|c|}
\hline & 63 & Guyuan & 53817 & 1753 & 888.31 & 0.093 & 0.107 & 29 & Increase & $1985-2013$ \\
\hline & 64 & Geermu & 52818 & 2807.6 & -745.96 & 0.272 & 0.000 & 53 & Significant decrease & $1961-2013$ \\
\hline & 65 & Xining & 52866 & 2295.2 & -1492.75 & 0.242 & 0.000 & 53 & Significant decrease & $1961-2013$ \\
\hline \multirow[t]{5}{*}{ Qinghai } & 66 & Yushu & 56029 & 3716.9 & -1420.61 & 0.137 & 0.006 & 53 & Significant decrease & $1961-2013$ \\
\hline & 67 & Gangcha & 52754 & 13301.5 & -1518.60 & 0.206 & 0.039 & 21 & Significant decrease & $1993-2013$ \\
\hline & 68 & Guoluo & 56043 & 3719 & -1345.84 & 0.044 & 0.360 & 21 & Decrease & $1993-2013$ \\
\hline & 69 & Jinan & 54823 & 170.3 & -1217.61 & 0.256 & 0.000 & 53 & Significant decrease & $1961-2013$ \\
\hline & 70 & Yantai & 54765 & 46.7 & 342.40 & 0.006 & 0.668 & 31 & Increase & 1961-1991 \\
\hline \multirow[t]{4}{*}{ Shandong } & 71 & Jining & 54915 & 40.7 & 139.44 & 0.001 & 0.908 & 28 & Increase & $1963-1990$ \\
\hline & 72 & Juxian & 54936 & 107.4 & -1179.91 & 0.172 & 0.044 & 24 & Significant decrease & $1990-2013$ \\
\hline & 73 & Fushan & 54764 & 53.9 & -765.00 & 0.069 & 0.239 & 22 & Decrease & $1992-2013$ \\
\hline & 74 & Taiyang & 53772 & 778.3 & -2003.20 & 0.420 & 0.000 & 53 & Significant decrease & $1961-2013$ \\
\hline \multicolumn{4}{|l|}{ Shanxi } & 1329 & 171660 & 010 & 0000 & & Sinnifinont dorro & \\
\hline & 15 & Houma & 53903 & 430.8 & $-1 / 40.09$ & 0.010 & 0.000 & & Slgnincant decrease & $1901-2013$ \\
\hline
\end{tabular}




\begin{tabular}{|c|c|c|c|c|c|c|c|c|c|c|}
\hline & 76 & Datong & 53487 & 1067.2 & -1438.20 & 0.286 & 0.000 & 53 & Significant decrease & $1961-2013$ \\
\hline & 77 & Xi'an & 57036 & 397.5 & -1922.94 & 0.394 & 0.000 & 45 & Significant decrease & 1961-2005 \\
\hline \multirow[t]{3}{*}{ Shaanxi } & 78 & Yan'an & 53845 & 958.5 & -683.19 & 0.023 & 0.482 & 24 & Decrease & $1990-2013$ \\
\hline & 79 & Ankang & 57245 & 290.8 & -382.06 & 0.007 & 0.700 & 24 & Decrease & $1990-2013$ \\
\hline & 80 & Longhua & 58367 & 2.8 & -2722.01 & 0.569 & 0.000 & 30 & Significant decrease & $1961-1990$ \\
\hline \multicolumn{11}{|l|}{ Shanghai } \\
\hline & 81 & Shanghai & 58362 & 5.5 & 218.65 & 0.004 & 0.778 & 23 & Increase & $1991-2013$ \\
\hline & 82 & Chengdu & 56294 & 506.1 & -2491.40 & 0.709 & 0.000 & 53 & Significant decrease & $1961-2003$ \\
\hline & 83 & Emeishan & 56385 & 13047.4 & 1617.30 & 0.413 & 0.000 & 53 & Significant increase & $1961-2013$ \\
\hline & 84 & Mianyang & 56196 & 522.7 & -417.17 & 0.020 & 0.412 & 36 & Decrease & $1978-2013$ \\
\hline & 85 & Panzhihua & 56666 & 1190.1 & 1026.94 & 0.015 & 0.584 & 22 & Increase & $1992-2013$ \\
\hline & 86 & Ganzhi & 56146 & 13393.5 & -397.13 & 0.017 & 0.587 & 20 & Decrease & 1994-2013 \\
\hline & 87 & Hongyuan & 56173 & 3491.6 & 1432.98 & 0.132 & 0.116 & 20 & Increase & 1994-2013 \\
\hline Tianjin & 88 & Tianjin & 54527 & 3.5 & -1555.36 & 0.313 & 0.000 & 53 & Significant decrease & $1961-2013$ \\
\hline
\end{tabular}




\begin{tabular}{|c|c|c|c|c|c|c|c|c|c|c|}
\hline & 89 & Lasha & 55591 & 3648.9 & -1604.63 & 0.155 & 0.004 & 53 & Significant decrease & $1961-2013$ \\
\hline \multirow{3}{*}{ Tibet } & 90 & Changdu & 56137 & 3315 & -591.98 & 0.028 & 0.233 & 53 & Decrease & $1961-2013$ \\
\hline & & & & & & & & & & \\
\hline & 91 & $\mathrm{Naqu}$ & 55299 & 4507 & 310.78 & 0.003 & 0.716 & 53 & Increase & $1961-2013$ \\
\hline \multirow{10}{*}{ Xinjiang } & 92 & Ge'er & 55228 & 4278.6 & 2486.62 & 0.069 & 0.093 & 42 & Increase & $1972-2013$ \\
\hline & 93 & Ruoqiang & 51777 & 887.7 & -663.74 & 0.091 & 0.029 & 53 & Significant decrease & $1961-2013$ \\
\hline & 94 & Hetian & 51828 & 1375 & -773.74 & 0.134 & 0.007 & 53 & Significant decrease & $1961-2013$ \\
\hline & 95 & Kuche & 51644 & 1081.9 & -2567.35 & 0.695 & 0.000 & 30 & Significant decrease & $1961-1990$ \\
\hline & 96 & Kasha & 51709 & 1289.4 & -1056.17 & 0.157 & 0.003 & 53 & Significant decrease & $1961-2013$ \\
\hline & 97 & Wulumuqi & 51463 & 935 & -968.37 & 0.269 & 0.000 & 53 & Significant decrease & $1961-2013$ \\
\hline & 98 & Yining & 51431 & 662.5 & -677.42 & 0.070 & 0.056 & 53 & Decrease & $1961-2013$ \\
\hline & 99 & Tulufan & 51573 & 34.5 & -1670.08 & 0.542 & 0.000 & 53 & Significant decrease & $1961-2013$ \\
\hline & 100 & A'ertai & 51076 & 735.3 & -257.98 & 0.023 & 0.282 & 53 & Decrease & $1961-2013$ \\
\hline & 101 & Hami & 52203 & 737.2 & -1205.00 & 0.320 & 0.000 & 53 & Significant decrease & $1961-2013$ \\
\hline
\end{tabular}




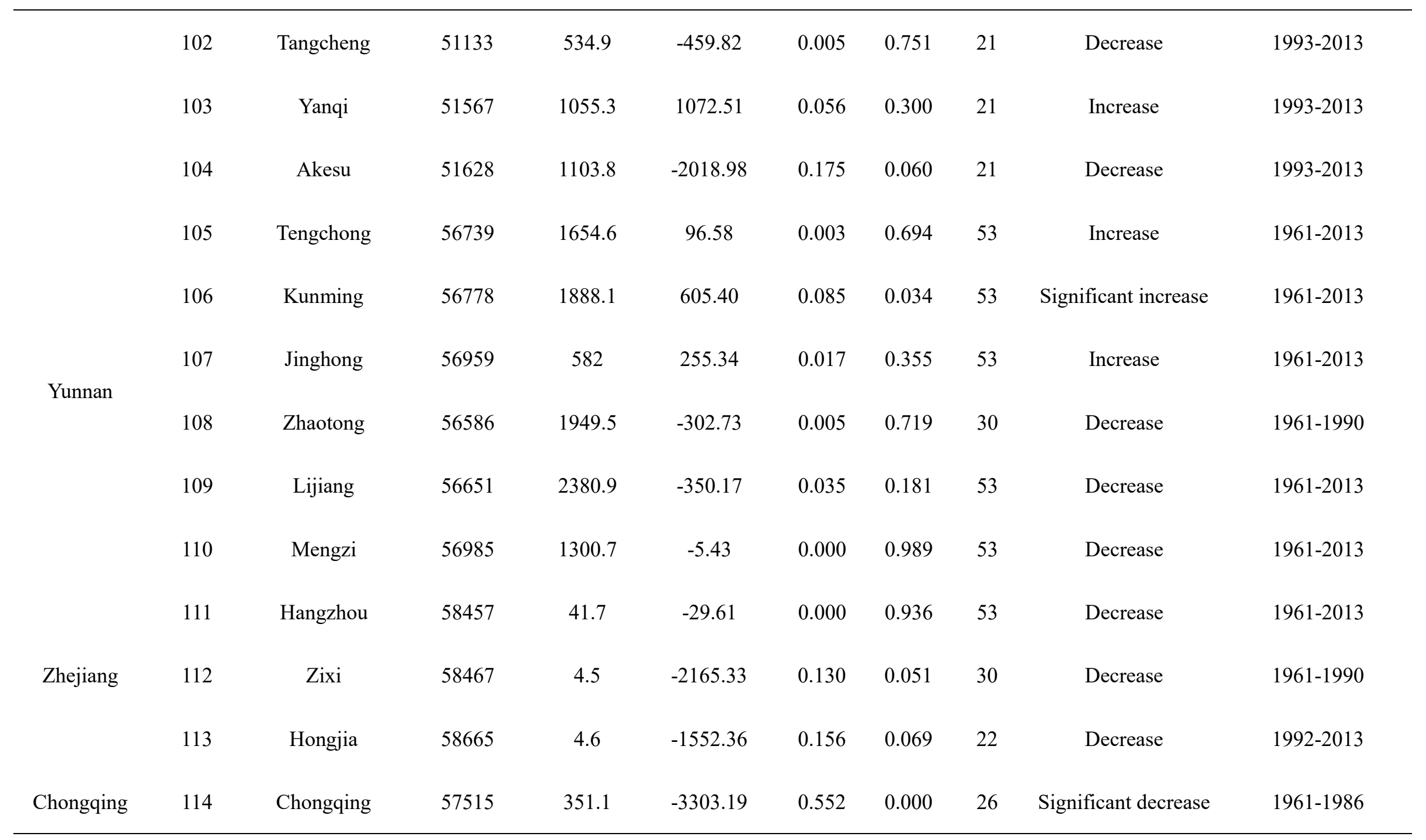




\begin{tabular}{|c|c|c|c|c|c|c|c|c|c|}
\hline 115 & Wanxian & 57432 & 186.7 & -2533.67 & 0.614 & 0.000 & 30 & Significant decrease & $1961-1990$ \\
\hline 116 & Shapingba & 57516 & 259.1 & 849.11 & 0.080 & 0.154 & 27 & Increase & $1987-2013$ \\
\hline
\end{tabular}

Table S2. Detailed information on 170 lakes (zones, province, number, name, latitude, longitude, lake area, mean water depth), the SDD from two different periods

(before 1995 [most before 1990] and after 2000), and the percentage change between them (comparing after 2005 with before 1995); a decrease is shown by a

downward arrow.

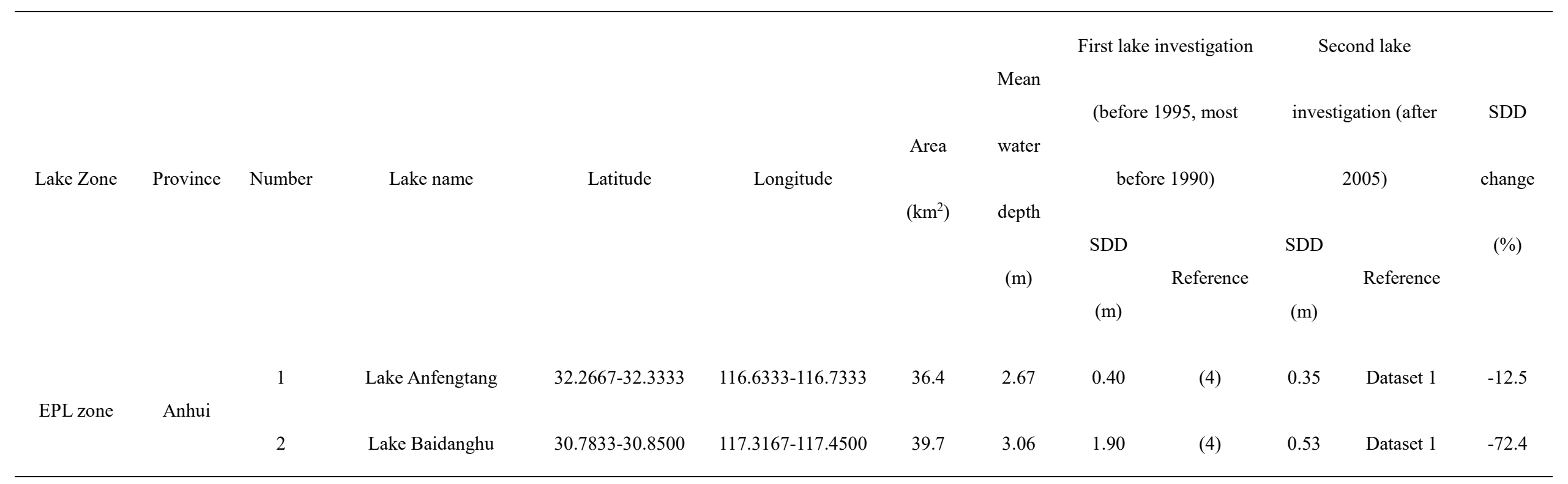




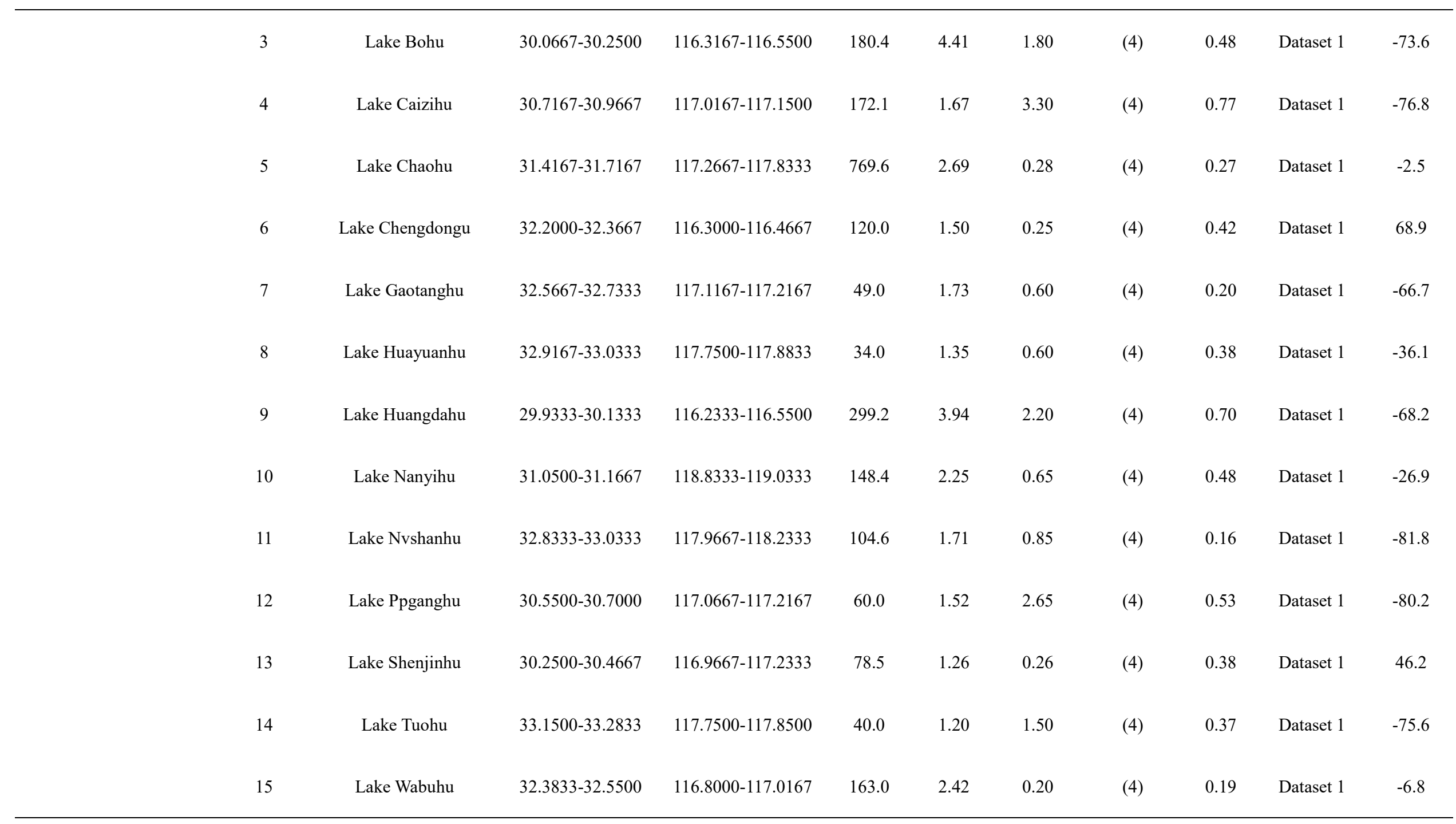




\begin{tabular}{|c|c|c|c|c|c|c|c|c|c|c|c|c|}
\hline & & 16 & Lake Wuchanghu & $30.2333-30.3333$ & $116.6000-116.8833$ & 100.5 & 3.43 & 1.00 & (4) & 0.42 & Dataset 1 & -57.9 \\
\hline & & 17 & Lake Xiangjian & $33.1000-33.2000$ & $117.2500-117.7500$ & 45.0 & 0.93 & 0.60 & (4) & 0.33 & Dataset 1 & -45.0 \\
\hline & & 18 & Lake Yihu & $32.7667-32.8333$ & $118.9833-119.0667$ & 18.0 & 1.70 & 0.27 & $(5)$ & 0.52 & Dataset 1 & 91.4 \\
\hline & & 19 & Lake Taipingh & $30.3486-30.4036$ & $118.0073-118.0213$ & 94.0 & 40.00 & 3.30 & $(6)$ & 3.10 & (7) & -6.1 \\
\hline \multirow{3}{*}{ EPL zone } & \multirow{3}{*}{ Beijing } & 20 & Guanting Reservoir & $40.2806-40.3857$ & $115.6038-115.7909$ & 238.0 & 10.00 & 1.02 & $(8)$ & 0.84 & (9) & -17.6 \\
\hline & & & & & & & & & & & & \\
\hline & & 21 & Miyun Reservoir & $40.4396-40.5538$ & $116.8257-117.0352$ & 180.0 & 30.00 & 2.50 & $(10)$ & 2.54 & (11) & 1.6 \\
\hline IMXL Zone & Gansu & 22 & Liujiaxia Reservoir & $35.7579-35.8998$ & $103.1800-103.2242$ & 130.0 & 31.00 & 1.39 & (12) & 1.78 & (13) & 28.1 \\
\hline \multirow{5}{*}{ EPL zone } & \multirow{5}{*}{ Guangdo } & 23 & Lake Liuhuahu & 23.1385 & 113.2461 & 0.3 & 1.57 & 0.20 & (4) & 0.33 & (14) & 65.0 \\
\hline & & 24 & Lake Liwanhu & 23.1228 & 113.2238 & 0.2 & 1.20 & 0.31 & (4) & 0.42 & (15) & 35.5 \\
\hline & & & & & & & & & & & & \\
\hline & & 25 & Lake Luhu & 23.1499 & 113.2770 & 0.2 & 2.50 & 0.38 & (4) & 0.37 & Unpub data & -2.6 \\
\hline & & 26 & Gaozhou Reservoir & 22.1444 & 111.0135 & 42.0 & 26.00 & 1.91 & (16) & 1.82 & (17) & -4.7 \\
\hline YGPL zone & Guizhou & 27 & Lake Caohai & $26.8167-26.8833$ & $104.2000-104.3000$ & 25.0 & 2.40 & 0.64 & (4) & 1.17 & (18) & 82.8 \\
\hline EPL zone & Hebei & 28 & Lake Baiyangdian & $38.7167-39.0333$ & $115.6000-116.0167$ & 366.0 & 2.84 & 1.50 & (4) & 0.79 & Dataset 1 & -47.3 \\
\hline
\end{tabular}




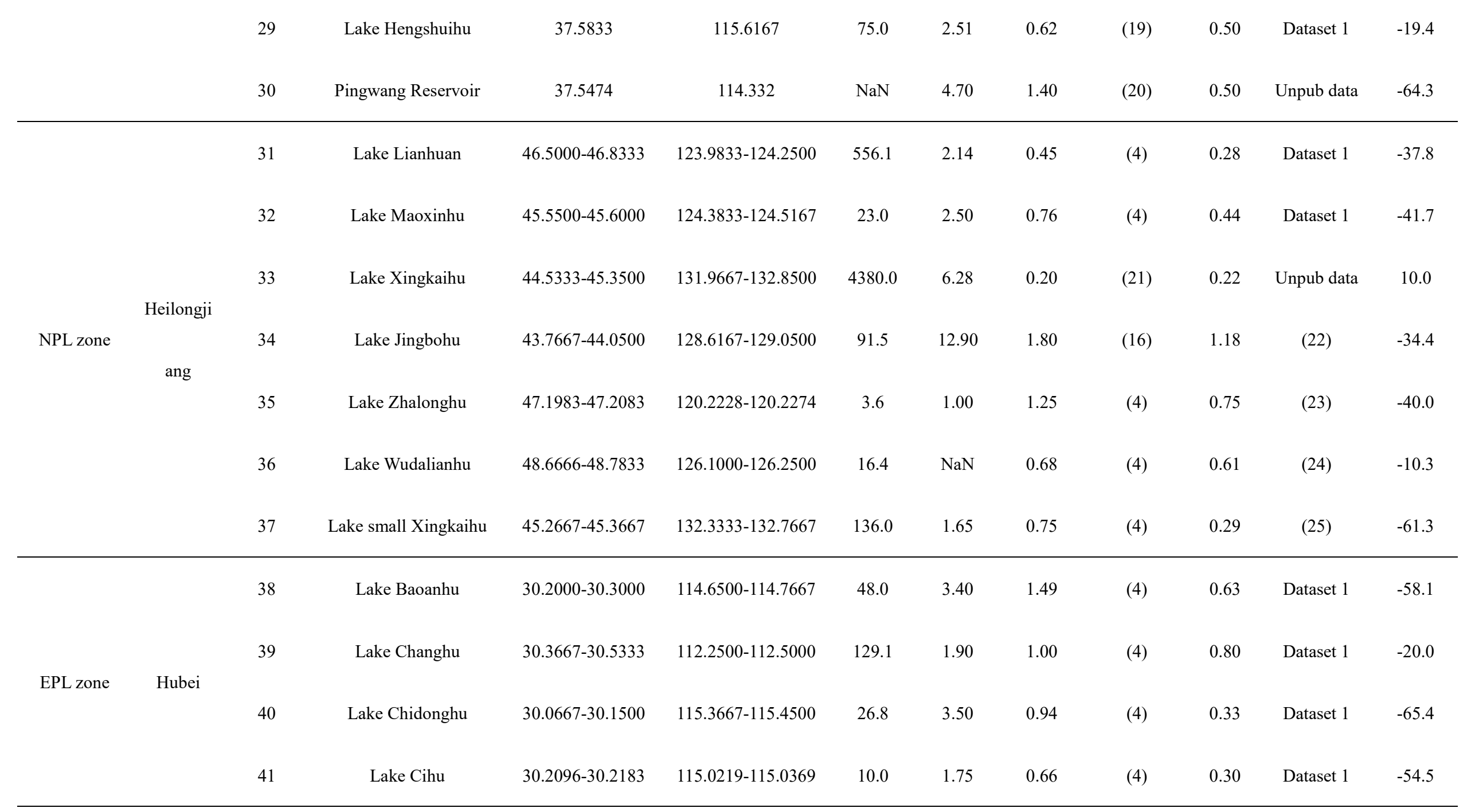




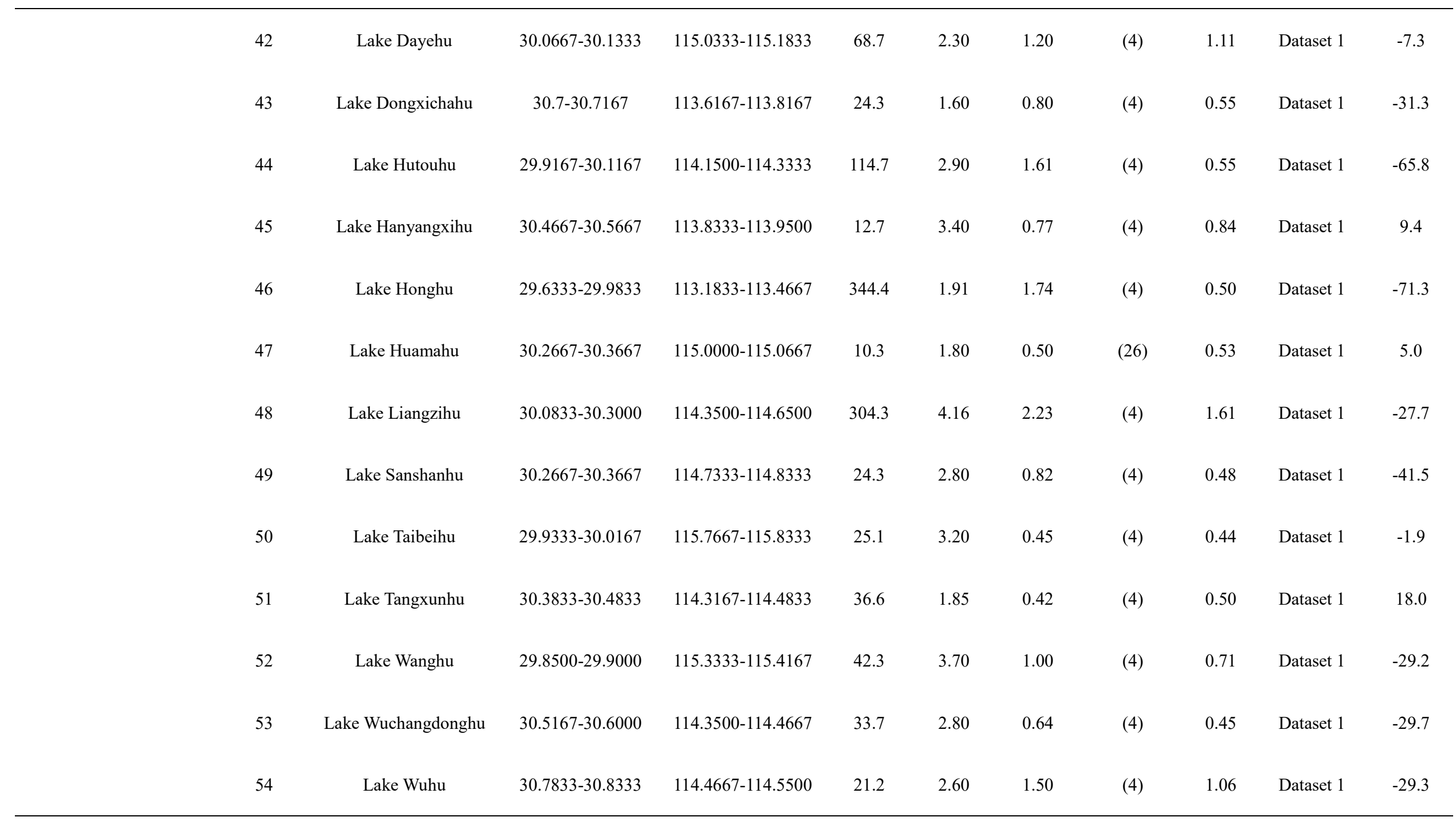




\begin{tabular}{|c|c|c|c|c|c|c|c|c|c|c|c|c|}
\hline & & 55 & Lake Xilianghu & $29.8500-30.0333$ & $114.0000-114.1667$ & 72.1 & 1.94 & 1.77 & (4) & 1.41 & Dataset 1 & -20.5 \\
\hline & & 56 & Lake Yanxihu & $30.5333-30.6167$ & $114.4500-114.5167$ & 11.8 & 1.90 & 0.76 & (4) & 0.55 & Dataset 1 & -28.3 \\
\hline & & 57 & Lake Zhangduhu & $30.6167-30.7000$ & $114.6667-114.8000$ & 35.2 & 1.20 & 1.50 & (4) & 0.42 & Dataset 1 & -72.2 \\
\hline & & 58 & Lake Longganhu & $29.8667-30.0833$ & $115.3167-116.2833$ & 316.2 & 3.78 & 2.15 & (4) & 0.59 & Dataset 1 & -72.8 \\
\hline & & 59 & Lake Houguanhu & $30.4667-30.5667$ & $113.9833-114.1500$ & 34.4 & 1.14 & 1.90 & (4) & 1.15 & $(27)$ & -39.5 \\
\hline & & 60 & Lake Qingshanhu & 30.3007 & 115.0447 & 1.1 & 1.35 & 0.34 & (4) & 0.30 & $(28)$ & -11.8 \\
\hline & & 61 & Lake Yanglanhu & 30.3878 & 114.8969 & 1.7 & 1.50 & 0.30 & (4) & 0.41 & (29) & 36.7 \\
\hline & & 62 & Lake Mushuihu & 30.5439 & 114.2255 & 3.6 & 1.30 & 0.25 & (4) & 0.44 & (27) & 76.0 \\
\hline & & 63 & Fuqiaohe Reservoir & $31.1759-31.2692$ & $114.8362-114.8728$ & 96.0 & 5.60 & 1.50 & $(30)$ & 1.40 & (30) & -6.7 \\
\hline & & 64 & Bailianhe Reservoir & 30.6128 & 115.5540 & 41.3 & $\mathrm{NaN}$ & 1.35 & (12) & 2.63 & $(31)$ & 94.8 \\
\hline & & 65 & Longping Reservoir & 30.1811 & 115.9150 & $\mathrm{NaN}$ & $\mathrm{NaN}$ & 1.60 & (12) & 2.20 & $(31)$ & 37.5 \\
\hline \multirow{3}{*}{ EPL zone } & \multirow{3}{*}{ Hunan } & 66 & Lake Beiminhu & $29.7000-29.7667$ & $111.8500-111.9167$ & 14.5 & 2.80 & 0.96 & (32) & 0.43 & Dataset 1 & -55.7 \\
\hline & & & & & & & & & & & & \\
\hline & & 67 & Lake Datonghu & $29.0833-29.2667$ & $112.4333-112.5833$ & 114.2 & 2.89 & 0.67 & (33) & 0.38 & Dataset 1 & -44.0 \\
\hline
\end{tabular}




\begin{tabular}{|c|c|c|c|c|c|c|c|c|c|c|c|c|}
\hline & & 68 & Lake Dongtinghu & $28.7333-29.5833$ & $111.8833-113.0833$ & 2432.5 & 6.39 & 0.85 & (4) & 0.48 & Dataset 1 & -43.6 \\
\hline & & 69 & Dongjiang Reservoir & $25.7408-25.9458$ & $113.3109-113.4416$ & 160.0 & 50.80 & 5.20 & (34) & 3.50 & (35) & -32.7 \\
\hline \multirow{9}{*}{ NPL zone } & \multirow{9}{*}{ Jilin } & 70 & Lake Chaganhu & $45.1667-45.3500$ & $124.0667-124.4500$ & 347.4 & 1.56 & 0.12 & $(4)$ & 0.17 & Dataset 1 & 38.3 \\
\hline & & 71 & Kulipao & 45.3725 & 124.4768 & $\mathrm{NaN}$ & $\mathrm{NaN}$ & 0.24 & (36) & 0.18 & Dataset 1 & -26.3 \\
\hline & & 72 & Xiaohuangpao & 45.6683 & 123.7285 & 42.0 & 2.25 & 0.72 & (37) & 0.28 & Dataset 1 & -60.7 \\
\hline & & 73 & Xinmiaopao & $45.1667-45.2167$ & $124.4333-124.5833$ & 31.0 & 2.00 & 0.20 & $(4)$ & 0.41 & Dataset 1 & 104.0 \\
\hline & & & & & & & & & & & & \\
\hline & & 74 & Yueliangpao & $45.6500-45.6000$ & $123.7000-124.0333$ & 206.0 & 2.30 & 0.54 & (12) & 0.28 & Dataset 1 & -48.1 \\
\hline & & 75 & Lake Songhuahu & $43.5234-43.7089$ & $126.8449-1271072$ & 554.0 & 35.00 & 1.10 & $(4)$ & 1.26 & $(38)$ & 14.5 \\
\hline & & 76 & Lake Jilinnanhu & 43.8525 & 125.3077 & 0.9 & 2.00 & 0.36 & (16) & 0.49 & (39) & 36.1 \\
\hline & & 77 & Longtou Reservoir & 42.9920 & 125.0904 & 2.7 & 7.00 & 0.75 & $(40)$ & 0.42 & $(41)$ & -44.0 \\
\hline \multirow{3}{*}{ EPL zone } & \multirow{3}{*}{ Jiangsu } & 78 & Lake Baimahu & $33.1500-33.3167$ & $119.0500-119.1833$ & 108.0 & 0.97 & 1.15 & $(4)$ & 0.67 & Dataset 1 & -42.0 \\
\hline & & 79 & Lake Chenghu & $31.1667-31.2333$ & $120.8000-120.8667$ & 45.0 & 1.83 & 0.54 & $(42)$ & 0.46 & Dataset 1 & -15.1 \\
\hline & & 80 & Lake Dazhonghu & $33.13333-33.1833$ & $119.7833-119.8500$ & 28.0 & 1.02 & 0.65 & $(4)$ & 0.55 & Dataset 1 & -15.4 \\
\hline
\end{tabular}




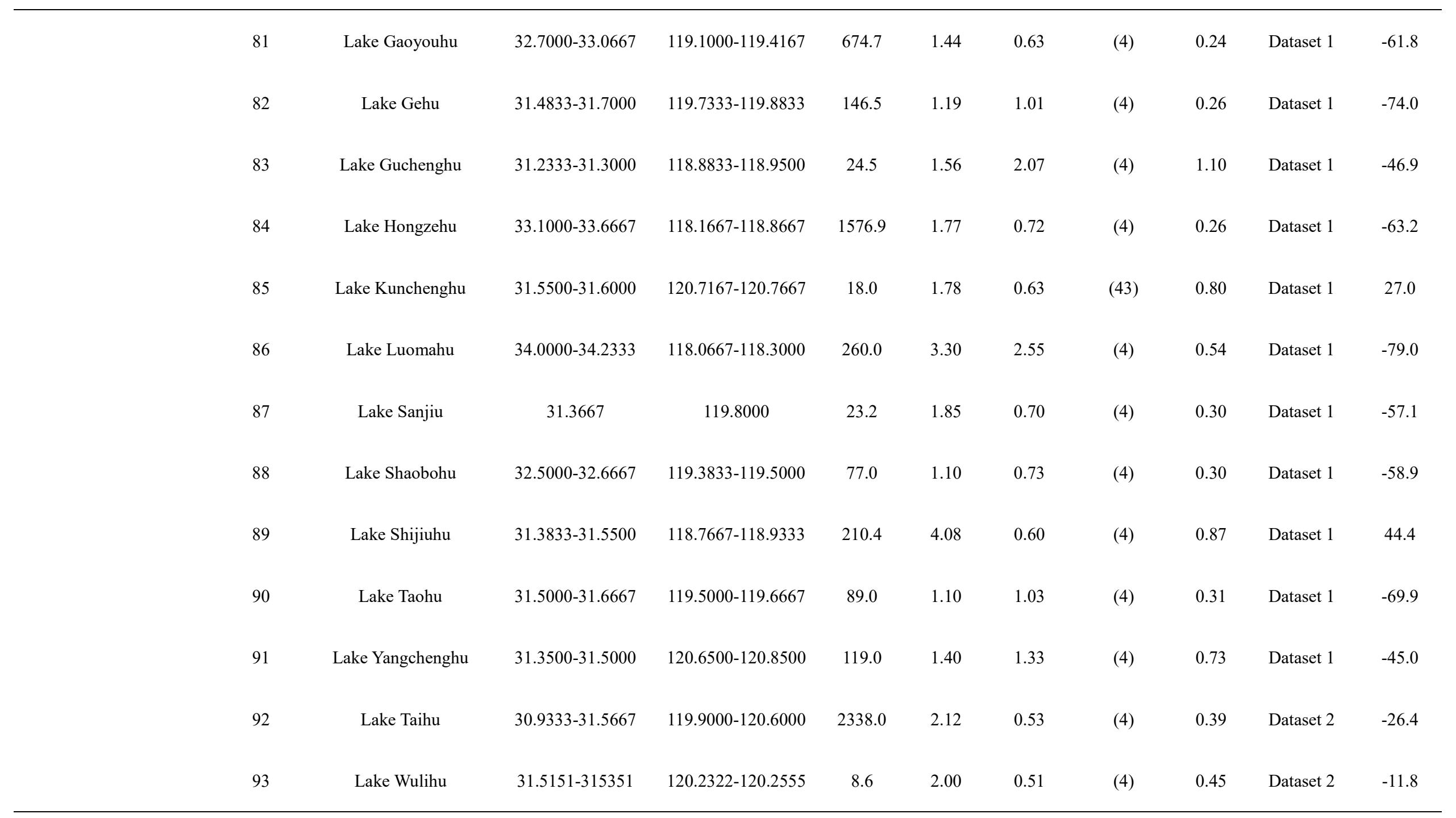




\begin{tabular}{|c|c|c|c|c|c|c|c|c|c|c|c|c|}
\hline & & 94 & Lake Xuwuhu & 32.0692 & 118.7984 & 3.7 & 1.50 & 0.27 & (16) & 0.20 & (44) & -25.9 \\
\hline & & 95 & Lake Shouxihu & 32.4226 & 119.4226 & 1.7 & 1.50 & 0.70 & (4) & 0.35 & (45) & -50.0 \\
\hline & & 96 & Lake Deshenghu & $32.9167-32.9500$ & $119.8333-119.9500$ & 15.0 & 0.67 & 0.65 & (4) & 0.30 & $(46)$ & -53.8 \\
\hline & & 97 & Lake Wugonghu & $31.5500-31.600$ & $120.7167-120.7667$ & 18.0 & 2.60 & 0.70 & (4) & 0.63 & $(46)$ & -10.0 \\
\hline & & 98 & Lake Baoyinghu & $31.1667-31.2333$ & $120.8000-120.8667$ & 192.1 & 1.13 & 1.05 & (4) & 0.84 & $(47)$ & -20.0 \\
\hline \multirow{9}{*}{ EPL zone } & \multirow{9}{*}{ Jiangxi } & 99 & Lake Chihu & $29.7333-29.8333$ & $115.6167-115.7333$ & 80.4 & 2.80 & 2.50 & $(48)$ & 0.76 & Dataset 1 & -69.5 \\
\hline & & 100 & Lake Nanbeihu & $29.6333-29.7000$ & $116.2000-116.2667$ & 24.7 & 4.65 & 0.50 & (4) & 0.40 & Dataset 1 & -20.0 \\
\hline & & 101 & Lake Poyanghu & $28.4000-29.7667$ & $115.8167-116.7667$ & 2933.0 & 5.10 & 0.85 & (4) & 0.41 & Dataset 1 & -51.4 \\
\hline & & 102 & Lake Qilihu & $29.6500-29.7000$ & $115.9167-115.9500$ & 16.2 & 2.20 & 0.40 & (4) & 0.45 & Dataset 1 & 12.5 \\
\hline & & & & & & & & & & & & \\
\hline & & 103 & Lake Saichenghu & $29.6500-29.7000$ & $115.7500-115.9167$ & 61.3 & 2.24 & 0.70 & (4) & 0.51 & Dataset 1 & -26.8 \\
\hline & & 104 & Lake Taibohu & $29.9500-30.0333$ & $116.6667-116.7667$ & 20.7 & 5.00 & 1.00 & (4) & 0.33 & Dataset 1 & -66.7 \\
\hline & & 105 & Lake Gantanghu & 29.7177 & 115.9869 & 2.4 & 1.40 & 0.56 & (16) & 0.22 & $(44)$ & -60.7 \\
\hline & & 106 & Hongmen Reservoir & $27.4745-27.4833$ & $116.7983-116.8952$ & 69.6 & 17.50 & 1.57 & (49) & 1.30 & (50) & -17.2 \\
\hline
\end{tabular}




\begin{tabular}{|c|c|c|c|c|c|c|c|c|c|c|c|c|}
\hline & & 107 & Caihe Reservoir & $42.2187-42.2512$ & $123.9866-124.0819$ & 17.0 & 35.30 & 1.16 & (12) & 1.00 & $(51)$ & -13.8 \\
\hline & & 108 & Dahuofang Reservoir & $41.8069-41.9491$ & $124.0872-124.3211$ & 110.4 & 19.20 & 1.71 & (12) & 2.25 & (51) & 31.6 \\
\hline & & 109 & Biliuhe Reservoir & $39.8143-39.9097$ & $122.4612-122.5343$ & 56.0 & 13.00 & 1.81 & $(52)$ & 2.35 & $(51)$ & 29.8 \\
\hline & & 110 & Tanghe Reservoir & $41.0048-41.0684$ & $123.3159-123.3636$ & 44.4 & 16.30 & 3.03 & (12) & 1.82 & $(51)$ & -39.9 \\
\hline \multirow[t]{7}{*}{ NPL zone } & Liaoning & & & & & & & & & & & \\
\hline & & 111 & Huanren Reservoir & $41.29244-41.3776$ & $125.5478-125.6327$ & 98.7 & 12.50 & 1.82 & (53) & 1.59 & $(51)$ & -12.6 \\
\hline & & 112 & Qinghe Reservoir & 42.5362 & 124.2176 & 46.0 & 13.70 & 1.04 & $(54)$ & 0.76 & $(55)$ & -26.9 \\
\hline & & 113 & Shuifeng Reservoir & $40.6241-40.4644$ & $120.9620-125.3929$ & 357.0 & 25.00 & 2.68 & (12) & 2.75 & $(56)$ & 2.6 \\
\hline & & 114 & Tiejia Reservoir & $40.0573-40.0955$ & $124.1415-124.1595$ & 21.6 & 11.90 & 2.48 & (12) & 1.76 & (57) & -29.0 \\
\hline & & 115 & Hasuhai & $40.5733-40.6366$ & $110.9321-110.9955$ & 29.7 & 1.70 & 0.88 & (58) & 0.64 & Dataset 1 & -27.3 \\
\hline & Inner & 116 & Daihai & $40.4667-40.6167$ & $112.5500-112.7833$ & 133.5 & 7.41 & 1.20 & $(4)$ & 0.85 & (59) & -29.2 \\
\hline & Mongolia & 117 & Lake Hulunhu & $48.5000-49.3333$ & $116.9667-117.8000$ & 2339.0 & 5.92 & 0.48 & (4) & 0.22 & $(60)$ & -54.2 \\
\hline & & 118 & Wuliangsuhai & $40.7833-41.0500$ & $108.7167-108.9500$ & 233.0 & 1.12 & 0.90 & (16) & 0.82 & (61) & -8.9 \\
\hline TPL zone & Qinghai & 119 & Lake Qinghaihu & $36.5333-37.2500$ & $99.6000-100.7833$ & 4340.0 & 17.90 & 5.00 & (4) & 3.27 & (62) & -34.6 \\
\hline
\end{tabular}




\begin{tabular}{|c|c|c|c|c|c|c|c|c|c|c|c|c|}
\hline & & 120 & Lake Elinghu & $34.7500-35.0833$ & $97.5167-97.9167$ & 610.7 & 17.60 & 3.50 & $(4)$ & 3.00 & $(63)$ & -14.3 \\
\hline \multirow{4}{*}{ EPL zone } & & 121 & Lake Dongpinghu & $35.7167-36.1167$ & $116.0333-116.3000$ & 148.0 & 1.59 & 0.83 & (4) & 0.72 & Dataset 1 & -13.2 \\
\hline & Shandon & 122 & Lake Nansihu & $34.4500-35.3333$ & $116.5667-117.3500$ & 1097.6 & 1.46 & 0.92 & (64) & 0.50 & Dataset 1 & -45.5 \\
\hline & \multirow[t]{2}{*}{ g } & 123 & Lake Matahu & $37.0500-37.0667$ & $118.0333-118.1500$ & 58.9 & 2.08 & 0.24 & $(4)$ & 0.35 & $(65)$ & 45.8 \\
\hline & & 124 & Zhoucun Reservoir & 34.9500 & 117.6833 & 8.5 & 9.80 & 1.45 & (66) & 0.98 & $(67)$ & -32.4 \\
\hline \multirow{3}{*}{ IMXL zone } & \multirow{3}{*}{ Shanxi } & 125 & Fenhe Reservoir & $38.0491-38.1243$ & $111.8545-111.9214$ & 32.0 & 6.50 & 1.27 & (12) & 1.63 & (68) & 28.3 \\
\hline & & & & & & & & & & & & \\
\hline & & 126 & Lake Jinyanghu & 37.7631 & 112.4987 & 4.8 & 4.00 & 0.80 & (12) & 0.64 & $(57)$ & -20.0 \\
\hline IMXL zone & Shaanxi & 127 & Hongjianzuo & $39.0667-39.1333$ & $109.8333-109.9333$ & 60.3 & 8.20 & 0.69 & $(4)$ & 0.83 & (69) & 20.3 \\
\hline \multirow[t]{2}{*}{ EPL zone } & Shanghai & 128 & Lake Dianshanhu & $31.0667-31.200$ & $120.8833-12.0167$ & 63.7 & 2.50 & 0.55 & $(4)$ & 0.42 & Dataset 1 & -23.9 \\
\hline & & 129 & Lake Qionghai & $27.7833-27.8667$ & $102.2667-102.3500$ & 31.0 & 10.32 & 2.13 & (4) & 1.32 & Dataset 1 & -38.0 \\
\hline \multirow[t]{2}{*}{ YGPL zone } & Sichuan & & & & & & & & & & & \\
\hline & & 130 & Shengzhong Reservoir & $31.5453-31.5938$ & $105.7597-105.6734$ & 56.0 & 18.20 & 2.20 & $(70)$ & 2.76 & $(71)$ & 25.5 \\
\hline EPL zone & Tianjin & 131 & Yuqiao Reservoir & $40.0206-40.0268$ & $117.5670-117.5997$ & 86.8 & 4.74 & 2.55 & (16) & 1.00 & (72) & -60.8 \\
\hline TPL zone & Tibet & 132 & Namucuo & $30.5000-30.9333$ & $90.2667-91.0500$ & 1961.5 & $\mathrm{NaN}$ & 9.00 & (4) & 8.00 & (73) & -11.1 \\
\hline
\end{tabular}




\begin{tabular}{|c|c|c|c|c|c|c|c|c|c|c|c|c|}
\hline & & 133 & Selincuo & $31.5667-31.9500$ & $88.5500-89.3500$ & 1628.0 & $\mathrm{NaN}$ & 7.50 & (4) & 2.30 & (73) & -69.3 \\
\hline & & 134 & Cuoe & $31.4167-31.7000$ & $88.5333-88.8333$ & 269.0 & $\mathrm{NaN}$ & 11.50 & (4) & 8.00 & (73) & -30.4 \\
\hline & & 135 & Dazhecuo & $31.8167-31.9833$ & $87.4167-87.6500$ & 244.7 & $\mathrm{NaN}$ & 7.20 & (4) & 6.00 & (73) & -16.7 \\
\hline & & 136 & Bangongcuo & $33.4333-33.9667$ & $78.4167-79.9333$ & 604.0 & $\mathrm{NaN}$ & 13.30 & Unpub data & 14.00 & (73) & 5.3 \\
\hline & & 137 & Bangdacuo & $34.9-35$ & $81.4833-81.6500$ & 106.5 & $\mathrm{NaN}$ & 1.30 & Unpub data & 1.30 & (73) & 0.0 \\
\hline & & 138 & Zigetangcuo & $32.0000-32.1500$ & $90.7333-90.9500$ & 191.4 & $\mathrm{NaN}$ & 6.70 & (4) & 3.00 & Unpub data & -55.2 \\
\hline & & 139 & Qixiangcuo & $32.4-32.5167$ & $89.8667-90.0667$ & 149.0 & $\mathrm{NaN}$ & 1.95 & (4) & 2.30 & Unpub data & 17.9 \\
\hline & & 140 & Cuona & $31.9167-32.1333$ & $91.4167-91.5500$ & 182.4 & $\mathrm{NaN}$ & 4.50 & (4) & 4.25 & Unpub data & -5.6 \\
\hline & & 141 & Lake Caiwobao & 43.5 & 87.9 & 30.0 & 4.18 & 0.40 & (74) & 0.22 & Dataset 1 & -45.0 \\
\hline & & 142 & Lake Jilihu & $46.8500-47.0000$ & $87.3333-87.5333$ & 174.0 & 9.90 & 2.80 & (4) & 1.83 & Dataset 1 & -34.6 \\
\hline IMXL zone & Xinjiang & 143 & Lake Sailimuhu & $44.5000-44.7000$ & $81.0833-89.6000$ & 453.0 & 46.40 & 8.50 & (4) & 10.50 & $(75)$ & 23.5 \\
\hline & & 144 & Lake Bositenghu & $41.8167-42.1333$ & $86.6833-87.4500$ & 992.2 & 8.08 & 1.74 & (76) & 2.10 & (77) & 20.7 \\
\hline & & 145 & Lake Hanasihu & $48.0500-48.2333$ & $86.9833-87.1167$ & 44.8 & 120.10 & 3.00 & (4) & 1.80 & Dataset 1 & -40.0 \\
\hline
\end{tabular}




\begin{tabular}{|c|c|c|c|c|c|c|c|c|c|c|c|c|}
\hline & & 146 & Buluntuohai & $47.0333-47.4167$ & $87.0333-87.5833$ & 753.0 & 8.00 & 2.40 & (4) & 2.60 & (78) & 8.3 \\
\hline & & 147 & Moguhu Reservoir & $44.4524-44.4758$ & $85.9187-85.9339$ & 31.2 & 4.30 & 0.64 & (16) & 0.65 & (79) & 1.6 \\
\hline & & 148 & Fukangtianchi & 43.8833 & 88.1333 & 4.9 & 60.00 & 9.00 & (4) & 1.10 & Dataset 1 & -87.8 \\
\hline & & 149 & Lake Akesaiqinhu & 35.2456 & 79.7935 & 165.8 & 7.75 & 3.00 & Unpub data & 1.00 & (73) & -66.7 \\
\hline \multirow{9}{*}{ YGPL zone } & \multirow{9}{*}{ Yunan } & 150 & Lake Dianchi & $24.6667-25.0333$ & $102.6000-102.7833$ & 298.0 & 2.93 & 1.00 & $(80)$ & 0.56 & $(81)$ & -44.0 \\
\hline & & 151 & Lake Fuxianhu & $24.3500-24.6333$ & $102.8167-102.9500$ & 211.0 & 89.60 & 7.10 & (4) & 4.35 & $(81)$ & -38.7 \\
\hline & & 152 & Lake Xingyunhu & $24.2833-24.3833$ & $102.7500-102.6000$ & 34.7 & 5.30 & 1.60 & (4) & 0.81 & $(81)$ & -49.4 \\
\hline & & 153 & Lake Yangzonghai & $24.8500-24.9667$ & $102.9667-103.0167$ & 31.7 & 19.50 & 4.50 & (4) & 2.62 & $(81)$ & -41.8 \\
\hline & & 154 & Lake Yilonghu & $23.6333-23.7000$ & $102.5000-102.6333$ & 38.0 & 2.40 & 1.85 & (4) & 0.95 & $(81)$ & -48.6 \\
\hline & & 155 & Lake Datunhai & $23.3833-23.4500$ & $103.2833-103.3333$ & 12.3 & 3.70 & 0.78 & (4) & 0.37 & $(81)$ & -52.6 \\
\hline & & 156 & Lake Erhai & $25.6000-25.9667$ & $100.1000-100.3000$ & 249.0 & 10.17 & 3.35 & (4) & 1.38 & $(81)$ & -58.8 \\
\hline & & 157 & Lake Chenghai & $26.4500-26.6333$ & $100.6333-100.6833$ & 77.2 & 25.70 & 4.10 & (4) & 1.42 & $(81)$ & -65.4 \\
\hline & & 158 & Lake Luguhu & $27.6833-27.7500$ & $100.7500-100.8333$ & 48.4 & 40.30 & 10.37 & (4) & 8.20 & (82) & -20.9 \\
\hline
\end{tabular}




\begin{tabular}{|c|c|c|c|c|c|c|c|c|c|c|c|c|}
\hline & & 159 & Lake Changqiaohai & $23.4000-23.4500$ & $103.3333-103.4000$ & 10.7 & 3.74 & 0.60 & (4) & 0.50 & $(81)$ & -16.7 \\
\hline & & 160 & Lake Qiluhu & $24.1333-24.2167$ & $102.7167-102.8167$ & 36.9 & 4.03 & 1.60 & (83) & 0.50 & (81) & -68.8 \\
\hline & & 161 & Lake Qingshuihai & $25.5833-25.6167$ & $103.1000-103.1167$ & 7.2 & 20.00 & 2.02 & (4) & 2.50 & $(81)$ & 23.8 \\
\hline & & 162 & Lake Cibihu & $26.1335-26.1861$ & 99.9252-99.9594 & 8.4 & 0.96 & 3.40 & $(80)$ & 3.65 & $(84)$ & 7.4 \\
\hline & & 163 & Lake Haixihai & $26.2778-26.2810$ & $99.9554-99.9693$ & 3.8 & 10.00 & 4.00 & (4) & 2.90 & $(84)$ & -27.5 \\
\hline & & 164 & Yunlongtianchi & 25.8704 & 99.2794 & 1.2 & 8.50 & 1.10 & (4) & 1.92 & $(84)$ & 74.5 \\
\hline & & 165 & Lake Jianhu & $26.4868-26.4892$ & $99.9342-99.9356$ & 4.8 & 4.50 & 2.60 & (4) & 0.79 & $(84)$ & -69.6 \\
\hline & & 166 & Lake Gejiuhu & 23.3699 & 103.1562 & 0.8 & 2.00 & 0.90 & $(83)$ & 0.69 & $(85)$ & -23.3 \\
\hline \multirow{5}{*}{ EPL zone } & \multirow{5}{*}{ Zhejiang } & 167 & Lake Dongqianhu & 29.8667 & 121.5667 & 21.0 & 2.00 & 0.66 & (4) & 0.68 & Dataset 1 & 3.5 \\
\hline & & 168 & Lake Hangzhouxihu & $30.2333-30.2667$ & $120.1333-120.1500$ & 5.7 & 1.84 & 0.51 & (4) & 0.45 & $(86)$ & -11.8 \\
\hline & & & & & & & & & & & & \\
\hline & & 169 & Lake Jiangxijianhu & 29.9667 & 120.2333 & 2.4 & 2.77 & 0.67 & (4) & 0.61 & $(87)$ & -9.0 \\
\hline & & 170 & Lake Qiandaohu & $29.4188-29.7184$ & $118.7085-119.1952$ & 570.0 & 30.00 & 8.17 & Dataset 2 & 5.00 & Dataset 2 & -38.8 \\
\hline
\end{tabular}

Dataset 1: The second national lake investigation, from 2006 to 2010 
Dataset 2: Long-term (more than 20 years) site-specific observations in Lake Fuxianh, Lake Qiandaohu, Lake Erhai and Lake Taihu,

Unpub data: Unpublished data

$\mathrm{NaN}$ represents no data.

Lake zones:

EPL, Eastern Plain Lake zone, covering Shanghai, Beijing and Tianjin municipalities, Hong Kong and Macao Special Administrative Regions, and Taiwan, Jiangxi,

Hunan, Hubei, Anhui, Henan, Shandong, Zhejiang, Jiangsu, Hainan, Fujian, Guangdong and Guangxi provinces.

IMXL, Inner Mongolia-Xinjiang Lake zone, covering Inner Mongolia, Xinjiang Uygur and Ningxia Hui Autonomous Regions, and Gansu, Shaanxi and Shanxi provinces.

NPL, Northeast Plain Lake zone, covered Liaoning, Jilin and Heilongjiang provinces.

TPL, Tibetan Plateau Lake zone, covering Qinghai province and Tibet Autonomous Region.

YGPL, Yunnan-Guizhou Plateau Lake zone, covering Chongqing Municipality, and Yunnan, Guizhou and Sichuan provinces. 
Table S3. Summary of linear fitting, statistical parameters from 61 long-term observations of decreasing SDD, from published literature $(n=54)$ and from the present study $(n=7)$.

\begin{tabular}{|c|c|c|c|c|c|c|c|c|}
\hline Nr. & Name & SDD observation method & Linear fitting & $r^{2}$ & $p$ & $n$ & Years & Reference \\
\hline 1 & Black Sea & In situ & $y=-0.090 x+191.392$ & 0.305 & $<0.001$ & 58 & $1955-1998$ & $(88)$ \\
\hline 2 & Little St. Germain Lake & In situ & $y=-0.051 x+104.201$ & 0.351 & $<0.005$ & 22 & $1991-2013$ & $(89)$ \\
\hline 3 & Baia River & In situ & $y=-0.023 x+46.510$ & 0.333 & $\leq 0.05$ & 12 & $1992-2007$ & $(90)$ \\
\hline 4 & Baltic sea + North sea & In situ & $y=-0.049 x+103.291$ & 0.677 & $<0.001$ & 72 & 1903-1998 & $(91)$ \\
\hline 5 & Mattawoman Creek & In situ & $y=-0.007 x+14.224$ & 0.180 & $<0.05$ & 25 & $1986-2010$ & $(92)$ \\
\hline 6 & Clear Lake, Iowa & In situ & $y=-0.010 x+19.671$ & 0.441 & $<0.005$ & 18 & $1896-2000$ & (93) \\
\hline 7 & Lake Modre & In situ & $y=-0.246 x+497.822$ & 0.451 & $<0.005$ & 19 & 1989-2010 & (94) \\
\hline 8 & Bohai Sea & Remote sensing & $y=-0.176 x+356.944$ & 0.862 & $=0.071$ & 4 & $1969-2008$ & (95) \\
\hline 9 & Lake Okareka & In situ & $y=-0.051 x+\Delta$ & 0.515 & $>0.05$ & 18 & $2000-2017$ & (96) \\
\hline 10 & Crystal lake & In situ & $y=-0.127 x+263.233$ & 0.681 & $<0.001$ & 27 & $1981-2011$ & (97) \\
\hline
\end{tabular}




\begin{tabular}{|c|c|c|c|c|c|c|c|c|}
\hline 11 & Lurefjorden & Calculation from beam & $y=-0.0012 x+13.746$ & 0.220 & $<0.001$ & 72 & $1935-2007$ & $(98)$ \\
\hline 12 & Lake Tahoe & In situ & $y=-0.214 x+448.543$ & 0.392 & $<0.001$ & 34 & $1968-2001$ & (99) \\
\hline 13 & Grane Langso & In situ & $y=-0.123 x+251.521$ & 0.699 & $<0.001$ & 24 & 1951-1994 & $(100)$ \\
\hline 14 & Gulf of Finland & In situ & $y=-0.039 x+84.791$ & 0.933 & $<0.001$ & 18 & 1944-1994 & $(101)$ \\
\hline 15 & Lake Giles & In situ & $y=-0.379 x+776.890$ & 0.635 & $<0.001$ & 27 & $1988-2014$ & $(102)$ \\
\hline 16 & Lake Lacawac & In situ & $y=-0.068 x+141.496$ & 0.267 & $<0.01$ & 27 & $1988-2014$ & $(102)$ \\
\hline 17 & Lake Annie & In situ & $y=-0.249 x+501.517$ & 0.764 & $<0.001$ & 25 & $1984-2008$ & $(103)$ \\
\hline 18 & Lake Okeechobee & In situ & $y=-0.007 x+15.161$ & 0.388 & $<0.001$ & 27 & $1973-2000$ & $(104)$ \\
\hline 19 & Emiquon Preserve & In situ & $y=-0.192 x+386.474$ & 0.678 & $<0.05$ & 7 & $2008-2014$ & $(105)$ \\
\hline 20 & Wadden Sea & In situ & $y=-0.052 x+109.382$ & 0.279 & $<0.005$ & 31 & $1977-2013$ & (106) \\
\hline 21 & Jordan & In situ & $y=-0.247 x+508.650$ & 0.484 & $<0.005$ & 18 & $1991-2008$ & (107) \\
\hline 22 & Spanish Mediterranean & In situ & $y=-0.094 x+203.397$ & 0.477 & $<0.001$ & 20 & 1973-1992 & (108) \\
\hline 23 & Conesus Lake & In situ & $y=-0.038 x+79.315$ & 0.794 & $<0.001$ & 12 & $1901-2014$ & (109) \\
\hline
\end{tabular}




\begin{tabular}{|c|c|c|c|c|c|c|c|c|}
\hline 24 & Lake Væng & In situ & $y=-0.058 x+117.710$ & 0.725 & $<0.001$ & 17 & $1998-2004$ & (110) \\
\hline 25 & Deep Bay, Hong Kong & In situ & $y=-0.044 x+88.563$ & 0.543 & $<0.05$ & 9 & $1998-2006$ & (111) \\
\hline 26 & Lake Nakaumi & In situ & $y=-0.029 x+58.585$ & 0.663 & $<0.001$ & 37 & $1932-2003$ & (112) \\
\hline 27 & Lake Donghu & In situ & $y=-0.029 x+58.788$ & 0.736 & $<0.001$ & 18 & $1979-1996$ & (113) \\
\hline 28 & Chesapeake Bay & In situ & $y=-0.022 x+46.374$ & 0.562 & $<0.001$ & 25 & $1985-2009$ & (114) \\
\hline 29 & Lake Płotycze & In situ & $y=-0.044 x+89.483$ & 0.391 & $<0.01$ & 16 & $1995-2012$ & (115) \\
\hline 30 & Seto Inland Sea & In situ & $y=-0.072 x+149.169$ & 0.832 & $<0.001$ & 16 & $1950-1992$ & (116) \\
\hline 31 & Kytai Lake & In situ & $y=-0.091 x+183.860$ & 0.668 & $<0.005$ & 10 & 2004-2013 & (117) \\
\hline 32 & Lake Peipsi & In situ & $y=-0.005 x+11.971$ & 0.562 & $<0.001$ & 56 & $1955-2010$ & (118) \\
\hline 33 & Lake Kasumigaura & In situ & $y=-0.017 x+35.037$ & 0.573 & $<0.001$ & 20 & $1988-2007$ & (119) \\
\hline 34 & Pärnu Bay & In situ & $y=-0.018 x+36.995$ & 0.417 & $<0.001$ & 48 & $1959-2010$ & $(120)$ \\
\hline 35 & California Current System & In situ & $y=-0.112 x+244.813$ & 0.230 & $<0.05$ & 26 & $1969-2007$ & $(121)$ \\
\hline 36 & Indian Sundarbans & In situ & $y=-0.272 x+564.958$ & 0.971 & $<0.001$ & 18 & $1980-2007$ & $(122)$ \\
\hline
\end{tabular}




\begin{tabular}{|c|c|c|c|c|c|c|c|c|}
\hline 37 & Marsdiep & In situ & $y=-0.008 x+17.561$ & 0.257 & $<0.05$ & 24 & $1974-2000$ & $(123)$ \\
\hline 38 & Lake Võrtsjärv & In situ & $y=-0.010 x+20.472$ & 0.234 & $<0.01$ & 28 & $1978-2007$ & (124) \\
\hline 39 & Lake Ladoga & In situ & $y=-0.007 x+17.350$ & l & l & / & $1905-2003$ & (125) \\
\hline 40 & Menai Strait & In situ & $y=-0.029 x+58.963$ & 0.368 & $<0.001$ & 22 & $1962-1988$ & $(126)$ \\
\hline 41 & Palić Lake** & In situ & $y=-0.004 x+7.236$ & 0.395 & $<0.001$ & 26 & $1977-2006$ & (127) \\
\hline 42 & Nyanza Gulf & In situ & $y=-0.013 x+26.138$ & 0.899 & $<0.05$ & 5 & $1927-1998$ & $(128)$ \\
\hline 43 & 26 boreal lakes & In situ & $y=-0.043 x+90.227$ & 0.304 & $<0.05$ & 18 & 1992-2009 & (129) \\
\hline 44 & Garcas Reservoir & In situ & $y=-0.094 x+188.338$ & 0.602 & $<0.05$ & 8 & $1997-2004$ & $(130)$ \\
\hline 45 & Lake George & In situ & $y=-0.221 x+448.978$ & 0.281 & $<0.05$ & 15 & 1981-1998 & (131) \\
\hline 46 & Lake Constance & In situ & $y=-0.035 x+75.128$ & 0.156 & $<0.05$ & 34 & $1975-2015$ & (132) \\
\hline 47 & Římov Reservoir & In situ & $y=-0.013 x+29.831$ & 0.182 & $<0.05$ & 32 & $1983-2014$ & (133) \\
\hline 48 & Great Barrier Reef & Remote sensing & $y=-0.020 x$ & l & $<0.005$ & 10 & $2002-2012$ & (134) \\
\hline 49 & 28 lakes in the Adirondack Park & In situ & $y=-0.063 x+\Delta$ & 0.48 & $<0.005$ & 17 & 1994-2012 & (135) \\
\hline
\end{tabular}




\begin{tabular}{|c|c|c|c|c|c|c|c|c|}
\hline 50 & Lake Maninjau & In situ & $y=-0.145 x+294.47$ & 0.59 & $<0.005$ & 13 & 2001-2019 & $(136)$ \\
\hline 51 & Lake Malawi & Remote sensing & $y=-0.052 x+117.94$ & 0.05 & $>0.05$ & 9 & 2003-2011 & $(137)$ \\
\hline 52 & West Yellow Sea & Remote sensing & $y=-0.164 x+337.45$ & 0.43 & $<0.01$ & 15 & $2002-2016$ & $(138)$ \\
\hline 53 & Lake Changdang & In situ & $y=-0.073 x+146.464$ & 0.879 & $<0.005$ & 7 & $1997-2010$ & (139) \\
\hline 54 & 10 lakes, Taihu catchment (excluding Lake Taihu) & In situ & $y=-0.011 x+23.176$ & 0.232 & $<0.05$ & 20 & $1991-2010$ & $(140)$ \\
\hline 55 & Lake Fuxianhu & In situ & $y=-0.060 x+125.178$ & 0.418 & $<0.001$ & 36 & $1980-2016$ & This study \\
\hline 56 & Lake Qiandaohu & In situ & $y=-0.109 x+223.931$ & 0.346 & $<0.001$ & 29 & $1988-2016$ & This study \\
\hline 57 & Lake Erhai & In situ & $y=-0.072 x+146.471$ & 0.678 & $<0.001$ & 32 & $1985-2016$ & This study \\
\hline 58 & Lake Liangzihu & In situ & $y=-0.078 x+158.727$ & 0.643 & $<0.001$ & 16 & $2001-2016$ & This study \\
\hline 59 & Lake Dainchi & In situ & $y=-0.008 x+15.724$ & 0.321 & $<0.001$ & 30 & $1982-2016$ & This study \\
\hline 60 & Lake Taihu & In situ & $y=-0.005 x+9.611$ & 0.156 & $<0.05$ & 25 & $1992-2016$ & This study \\
\hline 61 & Lake Gehu & In situ & $y=-0.028 x+57.432$ & 0.953 & $<0.001$ & 30 & $1985-2016$ & This study \\
\hline
\end{tabular}




\section{References:}

1. Q. Zhou et al., Seasonal and spatial distributions of euphotic zone and long-term variations in water transparency in a clear oligotrophic Lake Fuxian, China. Journal of Environmental Sciences 72, 185-197 (2018).

2. Y. Zhang et al., Thermal structure and response to long-term climatic changes in Lake Qiandaohu, a deep subtropical reservoir in China. Limnology and Oceanography 59, 1193-1202 (2014).

3. R. Ma et al., A half-century of changes in China's lakes: Global warming or human influence? Geophysical Research Letters 37, doi:10.1029/2010GL045514 (2010).

4. $\quad$ S. Wang, H. Dou, Lakes in China (Science Press, Beijing, 1998).

5. C. Fang et al., The water chemical characteristics and evaluation of fishery about Yangyihu Lake. Journal of Hubei Agricultural College 14, 45-48 (1994).

6. K. Qijun, X. Yicheng, Algae in Taipinghu Reservoir and its trophic level. Chinese Journal of Applied Ecology 3, 165-168 (1992).

7. S. Feng et al., Analysis on the temporal and spatial distribution of the primary productivity and its influencing factors in Lake Taiping( Reservoir),Anhui Province. Journal of Lake Sciences 28, 1361-1370 (2016).

8. G. Du, The study of trophic condition of Kwangting Reservoir. Journal of Beijing Teachers College (Natural Sciences Edition) 10, 56-61 (1989).

9. H. Li et al., The correlation of microcystins and water environment factors in Guanting Reservoir. Acta Ecologica Sinica 30, 1322-1327 (2010).

10. W. Zhang, J. Wang, D. Wu, G. Du, Trophic state and development trend of the Miyun Reservoir 
Water Resources Protection, 40-42 (1991).

11. X. L. Ge, X. D. Liu, X. C. Pan, L. I. Qi, S. G. Luo, The geochemical characteristics of water body in Miyun Reservoir. Rock \& Mineral Analysis 22, 44-48 (2003).

12. Z. He, Primary productivity and energy conversion efficiency of lakes and reservoirs in China Fisheries Science, 24-30 (1987).

13. B. A. Sang, J. Qin, M. A. Zheng-Xue, Relationship between characteristics of algal community and water quality in Liujiaxia Reservoir. Administration \& Technique of Environmental Monitoring 24, 29-34 (2012).

14. L. Yu, Z. Tan, P. Zhong, Z. Liu, Vertical distribution of phosphorus in the sediments of Liuhuahu lake, Guangzhou, southern China. Ecology and Environment 16, 1358-1363 (2007).

15. Y. Liang, Z. Luo, Investigation of eco-environment variety in Liwan Lake of Guangzhou after field curing. Guangzhou Environmental Sciences 20, 19-22 (2005).

16. Z. Li, H. Zhang, Trophic state index and its correlation with lake parameters. Acta Scientiae Circumstantiae 13, 391-397 (1993).

17. S. Y. Li et al., Study on the structure of phytoplankton community and Its relationships with environmental factors in Gaozhou Reservoir. Journal of Hydroecology 24, 16-24 (2013).

18. C. Zhou et al., Spatial-temporal variation of water quality in Caohai Lake. Journal of Hydroecology 37, 24-30 (2016).

19. B. Gu, S. Yue, Y. Zhao, Investigation report of aquatic vegetation in Hengshui Lake Hebei Fisheries, 9-11 (1990).

20. C. Ju, Water quality and phytoplankton in Pingwang reservoir and Liukuchi reservoir. Hebei Fisheries, 13-15 (1993). 
21. J. Zhou, Opinion on the fishery multiplication of Lake Xingkaihu. Helongjiang Fisheries 4, 1315 (1987).

22. J. Zhi-min, Y. Chun-wen, J. Jian-li, L. Zhu, A status investigation of water quality and eutrophication in Jingbo Lake. Water Resources Protection 25, 56-57 (2009).

23. F. Zhao, Y. U. Hong-Xian, M. A. Cheng-Xue, J. L. Song, Assessment of water quality in Zhalong Nature Reserve Zone by zooplankton communities. Chinese Journal of Fisheries 26, 41-45 (2013).

24. N. Wang et al., Status of water quality and succession changes in Lake Wudalianchi in the last 30 years. Journal of Lake Science 28, 1004-1009 (2016).

25. R. An, F. Wang, H. Yu, C. Ma, Characteristics and physical factors of phytoplankton functional groups in Small Xingkai Lake. Research of Environmental Sciences 29, 985-994 (2016).

26. C. Feng, H. Li, B. Yu, Y. Wang, S. Li, Studies on aquatic vascular plants in huama lake in east Hubei I. the aquatic flora. Journal of Wuhan Botanical Research 9, 363-371 (1991).

27. H. Liu, F. Xiong, L. Song, Y. Yang, Distribution of submerged macrophytes and eutrophication status of five lakes in Hanyang region of Wuhan, China. Freshwater Fisheries 47, 107-112 (2017).

28. J. Li, F. Ji, J. Hua, Community structure of phytoplankton and water quality assessment in summer in Lake Qingshan. Natural Science Journal of Harbin Normal University 29, 61-65 (2013).

29. J. Xiong, X. Mei, C. Hu, Relationship between the trophication classification and the community structure of rotifers in four lakes. Chinese Journal of Zoology 38, 8-14 (2003).

30. A. Zhu et al., Primary production of phytoplankton and its management in Fuqiaohe Reservoir, 
Hubei Province. Journal of Lake Sciences 19, 340-344 (2007).

31. B. L. Lu, P. C. Yan, X. H. Tian, W. B. Jin, Z. Y. Liu, Eutrophication and water characteristics of large and medium-sized reservoirs in Hubei Province. Resources \& Environment in the Yangtze Basin 21, 634-640 (2012).

32. W. He, Investigation on natural resources of Lake Beiminhu and preliminary exploration of fishery development. Current Fisheries 7-8 (1995).

33. H. Li, X. Cao, A summary of high yield aquaculture techniques in Lake Datong. Current Fisheries 25-26 (1992).

34. G. Zhou, An analysis on water quality of Dongjiang Reservoir in the upper part of Xiangjiang River. Advances in Environmental Science 2, 67-74 (1994).

35. Z. Y. Zhou et al., Preliminary studies on carbon sinking fisheries and ecological protection in Dongjiang Reservoir. Journal of Hydroecology 32, 79-84 (2011).

36. L. Sheng, M. Jiao, Phytoplankton primary production status and analysis of Kulipao in Qianguo county of Jilin province. Agriculture and Technology, 9-13 (1994).

37. F. Yang, Y. Zhang, Potamogeton crispus resource and its fishery utilization in the Songnen plain. Resource Science 15, 39-47 (1993).

38. Y. F. Shi, Investigation and assessment of eutrophication of Songhua Lake. Journal of Anhui Agricultural Sciences 36, 4669-4671 (2008).

39. J. Gao, X. Y. Wang, J. Feng, The dynamic changes of hydrochemical characteristics and the analysis of influencing factors about Nanhu Lake in Changchun. Environmental Science \& Management 31, 161-164 (2006).

40. L. Zhang, A. Wang, J. Zhao, A study on primary productivity of phytoplankton, biomass of 
plankton and fish productivity of silver carp and big-head in the Loutou Reservoir. Journal of Fisheries of China 5, 171-177 (1981).

41. S. Cui, Investigation and analysis of phytoplankton in Longtou Reservoir and countermeasures for fishery adjustment. Helongjiang Fisheries, 31-33 (2013).

42. W. Zhou, Y. Jin, Annual change of phytoplankton in Chenghu Lake. Journal of Lake Sciences 1, 62-70 (1989).

43. Z. Zhou, S. Cao, Investigation and utilization of benthic zoobenthos in Lake Kunchenghu, Changshu, Jiangsu Sichuan Journal of Zoology, 3-4 (1992).

44. C. Fan, C. Wang, Environmental geochemistry and eutrophication of lakes in the middle and lower reaches of the Yangtze River (Science Press Beijing, 2007).

45. Z. Chen, G. Dong, Y. Fan, C. Zhang, Analysis of water quality and eutrophication in Lake Shouxihu in Yangzhou. Jilin Agriculture, 151-152 (2011).

46. S. Zhu, L. Liu, J. Luo, Y. Yang, W. Yan, Correlation analysis between macrozoobenthos and environmental factors in lakes of Lixia River Area. Water Resources Protection 32, 99-104 (2016).

47. T. Xia, J. Chen, J. Long, Y. Huang, W. Di, Characteristic analysis of eutrophication on lakes in Gaobao water resources division in Jiangsu province. Environmental Monitoring and Forewarning 8, 40-45 (2016).

48. S. Guan, Q. Lang, A study on aqutic vegetation of Lake Chihu. Jiangxi Science 6, 44-50 (1988).

49. R. Zhao, H. Xu, C. Zhang, S. Xu, Investigation report of fishery resources in Hongmen Reservoir. Jiangxi Fishery Sciences and Technology, 11-19 (1994).

50. X. Jiang, L. Zhang, X. Yao, X. U. Huixian, L. I. Min, Greenhouse gas flux at reservoirs of 
Jiangxi Province and its influencing factors. Journal of Lake Sciences 29, 1000-1008 (2017).

51. H. Q. Yan et al., Evaluation and analysis of eutrophication in 6 domestic water supply reservoirs in Liaoning Province. Journal of Dalian Ocean University 31, 180-184 (2016).

52. Z. He, X. Wang, The hydrochemistry, plankton and primary productivity of Biliuhe Reservoir. Journal of Dalian Ocean University 7, 1-18 (1992).

53. G. Li, X. Dong, W. Zhang, Q. Yuan, D. Dong, A study of qualitative evaluation of ecoenvironment in Huanren Reservoir. Journal of Jilin Forestry Institute, 21-35 (1986).

54. S. Dong, L. Wang, W. Shi, Investigation on fishery biology of Qinghe Reservoir. Journal of Dalian Fisheries University, 45-56 (1986).

55. L. Zheng, Qinghe reservoir's water quality situation during the period of "twelfth five-year". Heilongjiang Environmental Journal 40, 47-49 (2016).

56. Z. Xiao et al., Primary productivity and fish productivity assessment in Shuifeng Reservoir. Chinese Journal of Fishery 30, 28-32 (2017).

57. H. Zhang, P. Liu, Eutrophication evaluation and control of large and medium reservoirs in Dandong. Liaoning Urban and Rural Environmental Science \& Technology 25, 12-14 (2005).

58. R. Han, Y. Yao, Water quality and pollution of Hasuhai Lake in Hohhot. Journal of Arid Land Resources \& Environment 8, 103-109 (1994).

59. Y. K. Zhou, I. Jia-Hu, Q. Huang, Z. D. Sun, H. J. Wang, Analysis on the trophic status of the Daihai lake in Inner Mongolia. Arid Land Geography 29, 42-46 (2006).

60. L. Liang et al., Analysis on the eutrophication trends and affecting factors in Lake Hulun,20062015. Journal of Lake Sciences 28, 1265-1273 (2016).

61. H. Ma, C. Li, S. Zhao, X. Zhou, Spatial-temporal distribution of water transparency and its 
relationships with environmental factors in Wuliangsu Lake, Inner Mongolia. Bulletin of Soil and Water Conservation 36, 273-277 (2016).

62. J. Yang, H. Qi, J. Shi, W. Yao, Investigation of aquatic vegetation in Qinghai Lake in summer Qinghai Science and Technology 15, 19-25 (2008).

63. S. J. Lu, Q. P. Zhou, Y. J. Wang, Comprehensive evaluation of water environment in the Eling Lake area. Journal of Environment \& Health 24, 598-599 (2007).

64. Z. Sun, The ecological environment and protecting measure of the Nansi Lake. Transactions of Oceanology \& Limnology, 18-27 (1989).

65. L. U. Yaping, M. Yao, L. Yang, Combination of sedimentary diatoms for instructing Mata Lake wetland nutrition characteristics. Journal of University of Jinan 29, 221-224 (2015).

66. S. Liu, H. Wang, F. Liu, On investigations and studies of mlementary productive forces in reservoirs with big and medium types in Zao Zhuang city. Journal of Zaozhuang Normal College (Natural Science Edition), 17-20 (1988).

67. H. Zhao, H. Cong, J. Ni, C. Zhu, Growth and decay of algae in Zhoucun reservoir under the hybrid stress conditions. Huanjing Kexue Xuebao 34, 2520-2525 (2014).

68. R. Wang, Evaluation and analysis of the water quality eutrophication of reservoirs along the Yellow River in Shanxi province. Shanxi Architecture 42, 212-213 (2016).

69. X. Q. Liu, Y. P. Wang, Evaluation of the eutrophication in Hongjiannao Lake. Yellow River 36, 76-78 (2014).

70. C. Zhan, Trend analysis of eutrophication in Shengzhong Reservoir Sichuan Environment, 6371 (1989).

71. Y. Zuo, T. Li, C. Li, N. Yin, Study on eutrophication of Shengzhong reservoir in Sichuan 
province based on integrated water quality index. Journal of Agricultural Resources and Environment, 83-85 (2012).

72. D. Wu, H. Wang, Z. Zhang, Investigation of summer plankton community structure in Yuqiao Reservoir,Tianjin. Journal of Lake Sciences 25, 735-742 (2013).

73. C. Liu et al., Remote sensing-based estimation of lake water clarity on the Tibetan Plateau. Progress in Geography 36, 597-609 (2017).

74. A. Lu, The status quo of the major lakes eutrophication of Urumqi region. Arid Environmental Monitoring 7, 224-226 (1993).

75. Z. J. Chen, J. Zhu, H. Y. Xin, Preliminary evaluation of hydrochemistry characteristics and water quality status quo of Sailimu Lake. Desert \& Oasis Meteorology 2, $46-48$ (2008).

76. X. Jin, H. Liu, Q. Tu, Lake eutrophication in China (China Environmental Science Press, 1990).

77. M. Wang et al., Phytoplankton absorption and chlorophyll-specific absorption coefficients characteristics of different trophic level lakes. Journal of Lake Sciences 25, 505-513 (2013).

78. Y. Dong et al., Research on water quality and trophic level in Wulungu Lake. Journal of Shanghai Fisheries University 17, 564-569 (2008).

79. T. Chengfeng, Water quality status and eutrophication analysis of the four major reservoirs in the middle reaches of the Manasi River Water Conservancy Science and Technology and Economy, 73-74 (2015).

80. H. Li, A study on the lake vegetation of Yunnan Plateau. Acta Botanica Yunnanica 2, 113-141 (1980).

81. Y. Lin Zhang, E. Lou Zhang, M. Liang Liu, X. Wang, B. Qiang Qin, Variation of chromophoric dissolved organic matter and possible attenuation depth of ultraviolet radiation in Yunnan 
Plateau lakes. Limnology 8, 311-319 (2007).

82. Y. X. Dong, Z. Z. Wang, Zooplankton community structure and Its seasonal variation in the surface water of Lugu Lake. Journal of Hydroecology 35, 38-45 (2014).

83. L. Shang-Hao et al., Limnological survey of the lakes of Yunan plateau. Oceanologia Et Limnologia Sinica 5, 87-114 (1963).

84. J. L. Zhang, L. Zhao, J. F. Nie, Research on spatial distribution of water qualities of small lakes in Yunnan Province. Environmental Science Survey 34, 26-34 (2015).

85. L. A. Wang, Y. Zhang, Suggestions on the SD and chl. a control standards in major lakes of Yunnan Province. Journal of Lake Sciences 18, 86-90 (2006).

86. Y. Zhang et al., The light condition and affect factors in Hangzhou west lake. Resources \& Environment in the Yangtze Basin 14, 744-749 (2005).

87. G. S. Pan, J. Q. Cai, X. P. Zhou, Present eutrophic conditions of headwater of Jianhu lake and corresponding prevention measure. China Public Health 19, 1104-1105 (2003).

88. A. S. Kukushkin, Long-term seasonal variability of water transparency in the surface layer of the deep part of the Black Sea. Russian Meteorology \& Hydrology 39, 178-186 (2014).

89. D. M. Robertson, M. W. J. Rose, M. P. C. Reneau, Interannual and long-term changes in the trophic state of a multibasin lake: effects of morphology, climate, winter aeration, and beaver activity. Canadian Journal of Fisheries \& Aquatic Sciences 73, 445-460 (2016).

90. L. A. Espínola, C. V. Mintevera, H. F. Júlio Junior, L. N. Santos, K. O. Winemiller, Evaluation of factors associated with dynamics of Cichla ocellaris invasion of the Upper Paraná River floodplain system, Brazil. Marine \& Freshwater Research 66, 33-40 (2015).

91. N. Dupont, D. Aksnes, Centennial changes in water clarity of the Baltic Sea and the North Sea. 
Estuarine, Coastal and Shelf Science 131, 282-289 (2013).

92. W. R. Boynton et al., Multi-decade responses of a tidal creek system to nutrient load reductions: Mattawoman Creek, Maryland USA. Estuaries \& Coasts 37, 111-127 (2014).

93. C. J. Egertson, J. A. Kopaska, J. A. Downing, A century of change in macrophyte abundance and composition in response to agricultural eutrophication. Hydrobiologia 524, 145-156 (2004).

94. M. Kraska, P. Klimaszyk, R. Piotrowicz, Anthropogenic changes in properties of the water and spatial structure of the vegetation of the lobelia lake Lake Modre in the Bytów Lakeland. Oceanological and Hydrobiological Studies 42, 302-313 (2013).

95. S. Shang et al., Changes in water clarity of the Bohai Sea: Observations from MODIS. Remote Sensing of Environment 186, 22-31 (2016).

96. M. K. Lehmann, U. Nguyen, K. Muraoka, M. G. Allan, Regional trends in remotely sensed water clarity over 18 years in the Rotorua Lakes, New Zealand. New Zealand Journal of Marine and Freshwater Research 53, 513-535 (2019).

97. K. C. Rose, L. A. Winslow, J. S. Read, G. J. Hansen, Climate-induced warming of lakes can be either amplified or suppressed by trends in water clarity. Limnology and Oceanography Letters 1, 44-53 (2016).

98. D. L. Aksnes et al., Coastal water darkening and implications for mesopelagic regime shifts in Norwegian fjords. Marine Ecology Progress Series 387, 39-49 (2009).

99. A. D. Jassby, J. E. Reuter, C. R. Goldman, Determining long-term water quality change in the presence of climate variability: Lake Tahoe (USA). Canadian Journal of Fisheries and Aquatic Sciences 60, 1452-1461 (2003).

100. T. Riis, K. Sand-Jensen, Development of vegetation and environmental conditions in an 
oligotrophic Danish lake over 40 years. Freshwater Biology 40, 123-134 (1998).

101. D. Lajus, J. Glazkova, D. Sendek, V. Khaitov, J. Lajus, Dynamics of fish catches in the eastern Gulf of Finland (Baltic Sea) and downstream of the Neva River during the 20th century. Aquatic Sciences 77, 411-425 (2015).

102. C. E. Williamson et al., Ecological consequences of long-term browning in lakes. Scientific Reports 5, doi: 10.1038/srep18666 (2015).

103. E. E. Gaiser, N. D. Deyrup, R. W. Bachmann, L. E. Battoe, H. M. Swain, Effects of climate variability on transparency and thermal structure in subtropical, monomictic Lake Annie, Florida. Fundamental and Applied Limnology 175, 217-230 (2009).

104. K. E. Havens, R. T. James, T. L. East, V. H. Smith, N: P ratios, light limitation, and cyanobacterial dominance in a subtropical lake impacted by non-point source nutrient pollution. Environmental Pollution 122, 379-390 (2003).

105. T. D. VanMiddlesworth et al., Fish community succession and biomanipulation to control two common aquatic ecosystem stressors during a large-scale floodplain lake restoration. Hydrobiologia 804, 73-88 (2017).

106. C. J. Philippart et al., Four decades of variability in turbidity in the western Wadden Sea as derived from corrected Secchi disk readings. Journal of Sea Research 82, 67-79 (2013).

107. K. E. Strock, N. Theodore, W. G. Gawley, A. C. Ellsworth, J. E. Saros, Increasing dissolved organic carbon concentrations in northern boreal lakes: Implications for lake water transparency and thermal structure. Journal of Geophysical Research: Biogeosciences 122, 1022-1035 (2017).

108. N. Marbà, C. M. Duarte, Interannual changes in seagrass (Posidonia oceanica) growth and environmental change in the Spanish Mediterranean littoral zone. Limnology and 
Oceanography 42, 800-810 (1997).

109. J. C. Makarewicz, T. W. Lewis, J. A. Makarewicz, Invasive species induced food web disruption, alternative regimes, and cyanobacteria dominance in a pelagic food web: a case history. Inland Waters 6, 35-53 (2016).

110. M. Søndergaard et al., Lake restoration: successes, failures and long-term effects. Journal of Applied Ecology 44, 1095-1105 (2007).

111. J. Xu et al., Long-term and seasonal changes in nutrients, phytoplankton biomass, and dissolved oxygen in Deep Bay, Hong Kong. Estuaries and Coasts 33, 399-416 (2010).

112. J.-i. Hiratsuka, M. Yamamuro, Y. Ishitobi, Long-term change in water transparency before and after the loss of eelgrass beds in an estuarine lagoon, Lake Nakaumi, Japan. Limnology 8, 5358 (2007).

113. Y. Yufeng, H. Xiangfei, L. Jiankang, Long-term changes in crustacean zooplankton and water quality in a shallow, eutrophic Chinese lake densely stocked with fish. Hydrobiologia 391, 193201 (1998).

114. C. L. Gallegos, P. J. Werdell, C. R. McClain, Long-term changes in light scattering in Chesapeake Bay inferred from Secchi depth, light attenuation, and remote sensing measurements. Journal of Geophysical Research: Oceans 116, doi:10.1029/2011JC007160 (2011).

115. W. Pęczuła, A. Szczurowska, Long-term changes in phytoplankton in a humic lake in response to the water level rising: the effects of beaver engineering on a freshwater ecosystem. Knowledge and Management of Aquatic Ecosystems 410, 1-13 (2013).

116. T. Komatsu, Long-term changes in the Zostera bed area in the Seto Inland Sea (Japan), 
especially along the coast of the Okayama Prefecture. Oceanol Acta 20, 209-216 (1997).

117. M. Dzhurtubaev, T. Urbanskaya, Y. Dzhurtubaev, Long-term dynamics of hydrological and hydro-chemical indicators of Kytai Lake (Odessa region, Ukraine). Biosystems Diversity 24, 384-391 (2016).

118. K. Kangur et al., Long-term effects of extreme weather events and eutrophication on the fish community of shallow Lake Peipsi (Estonia/Russia). Journal of Limnology 72, 376-387 (2013).

119. M. M. Terrel, T. Fukushima, B. Matsushita, K. Yoshimura, A. Imai, Long-term light environment variability in Lake Biwa and Lake Kasumigaura, Japan: modeling approach. Limnology 13, 237-252 (2012).

120. K. Laur, H. Ojaveer, M. Simm, R. Klais, Multidecadal dynamics of larval gobies Pomatoschistus spp. In response to environmental variability in a shallow temperate bay. Estuarine, Coastal and Shelf Science 136, 112-118 (2014).

121. D. L. Aksnesa, M. D. Ohman, Multi-decadal shoaling of the euphotic zone in the southern sector of the California Current System. Limnology and Oceanography 54, 1272-1281 (2009).

122. A. Mitra, A. Gangopadhyay, A. Dube, A. C. Schmidt, K. Banerjee, Observed changes in water mass properties in the Indian Sundarbans (northwestern Bay of Bengal) during 1980-2007. Current Science 97, 1445-1452 (2009).

123. G. C. Cadée, J. Hegeman, Phytoplankton in the Marsdiep at the end of the 20th century; 30 years monitoring biomass, primary production, and Phaeocystis blooms. Journal of Sea Research 48, 97-110 (2002).

124. K. Tominga, P. Noges, H. Arst, T. Kõiv, T. Noges, Reconstruction of long-term changes of the underwater light field in large shallow lakes Peipsi and Võrtsjärv, North-East Europe. 
Proceedings of the Estonian Academy of Sciences 62, 202-212 (2013).

125. M. A. Naumenko, "Seasonality and trends in the Secchi disk transparency of Lake Ladoga" in European Large Lakes Ecosystem changes and their ecological and socioeconomic impacts. (Springer, 2008), pp. 59-65.

126. S. Kratzer, S. Buchan, D. Bowers, Testing long-term trends in turbidity in the Menai Strait, North Wales. Estuarine, Coastal and Shelf Science 56, 221-226 (2003).

127. I. Gržetić, N. Čamprag, The evolution of the trophic state of the Palić Lake (Serbia). Journal of the Serbian Chemical Society 75, 717-732 (2010).

128. H. Lung'Ayia, L. Sitoki, M. Kenyanya, The nutrient enrichment of Lake Victoria (Kenyan waters). Hydrobiologia 458, 75-82 (2001).

129. D. G. Angeler, S. Drakare, Tracing alpha, beta, and gamma diversity responses to environmental change in boreal lakes. Oecologia 172, 1191-1202 (2013).

130. D. D. C. Bicudo et al., Undesirable side-effects of water hyacinth control in a shallow tropical reservoir. Freshwater Biology 52, 1120-1133 (2007).

131. J. M. Gunn, E. Snucins, N. D. Yan, M. T. Arts, Use of water clarity to monitor the effects of climate change and other stressors on oligotrophic lakes. Environmental Monitoring and Assessment 67, 69-88 (2001).

132. F. Murphy, K. Schmieder, L. Baastrup-Spohr, O. Pedersen, K. Sand-Jensen, Five decades of dramatic changes in submerged vegetation in Lake Constance. Aquatic Botany 144, 31-37 (2018).

133. P. Znachor et al., Multiple long-term trends and trend reversals dominate environmental conditions in a man-made freshwater reservoir. Science of The Total Environment 624, 24-33 
(2018).

134. S. Weeks et al., Satellite-derived photic depth on the Great Barrier Reef: spatio-temporal patterns of water clarity. Remote Sensing 4, 3781-3795 (2012).

135. T. H. Leach, L. A. Winslow, N. M. Hayes, K. C. Rose, Decoupled trophic responses to longterm recovery from acidification and associated browning in lakes. Global Change Biology 25, 1779-1792 (2019).

136. F. Setiawan, B. Matsushita, R. Hamzah, D. Jiang, T. Fukushima, Long-term change of the secchi disk depth in Lake Maninjau, Indonesia shown by Landsat TM and ETM+ data. Remote Sensing 11, 2875 (2019).

137. A. Vundo et al., An overall evaluation of water transparency in Lake Malawi from MERIS data. Remote Sensing 11, 279 (2019).

138. L. Li et al., Assessment of the impacts from the world's largest floating macroalgae blooms on the water clarity at the west Yellow Sea using MODIS data (2002-2016). IEEE Journal of Selected Topics in Applied Earth Observations and Remote Sensing 11, 1397-1402 (2018).

139. F.-f. Wang et al., A study on the nutrition status evaluation and algal limiting factor in Lake Changdang the last 15-years. Environmental Science \& Technology 35, 353-357 (2012).

140. X. Chen, L. I. Xiaoping, X. Cheng, F. Wang, W. Chen, Eutrophication evolution of typical small and medium-sized lakes in Lake Taihu basin (1991 2010). Journal of Lake Sciences 25, 846$853(2013)$ 